\title{
A THERMOCHROMIC LIQUID CRYSTALS IMAGE ANALYSIS TECHNIQUE TO INVESTIGATE TEMPERATURE POLARIZATION IN SPACER-FILLED CHANNELS FOR MEMBRANE DISTILLATION
}

\author{
A. Tamburini", P. Pitò , A. Cipollina ${ }^{*}$, G. Micale ${ }^{*}$, M. Ciofalo ${ }^{* *}$ \\ *Dipartimento di Ingegneria Chimica, Gestionale, Informatica, Meccanica \\ ** Dipartimento dell'Energia, Ingegneria dell'Informazione e Modelli Matematici \\ Università degli Studi di Palermo, Viale delle Scienze, 90128 Palermo, Italy
}

\section{ABSTRACT}

The analysis of flow fields and temperature distributions is of paramount importance in the development and optimization of new spacer-filled channel geometries for Membrane Distillation modules. The literature reports only few studies on the experimental characterization of such channels and, to the authors' knowledge, none of them presents local information concerning the temperature distribution on the membrane surface. In the present work, a non-intrusive experimental technique named TLC-IA-TP is presented: it is based on the use of Thermochromic Liquid Crystals (TLCs) and digital Image Analysis (IA) and it is applied here for the first time to the analysis of Temperature Polarization (TP) in spacer-filled channels typically adopted in thermally-driven membrane separation processes. In particular, this technique allows the local distribution of convective heat transfer coefficients to be determined, thus providing (i) useful indications on strengths and weaknesses of some spacer arrangements and (ii) valuable benchmark data for Computational Fluid Dynamics (CFD) studies. For the purpose of the present work, the 
technique's fundamentals are presented, along with a comprehensive assessment of the technique's accuracy. Results of some preliminary measurements on commercial spacers are also reported.

Keywords: Membrane distillation, Temperature polarization, Thermochromic Liquid Crystals, Digital Image Analysis, Spacer filled channel 


\section{INTRODUCTION AND LITERATURE REVIEW}

Membrane distillation (MD) is a relatively new process that is being investigated worldwide as a low cost, energy saving alternative to conventional separation processes such as distillation and reverse osmosis [1,2]. Nowadays, the possibility of driving the process via solar thermal energy and waste heat has further enhanced the interest towards this technique [3-7]. MD is a separation technique combining the features of both thermal and membrane-based distillation processes. Thermal energy causes the liquid to vaporise in an evaporator channel, while a hydrophobic microporous membrane allows the passage of vapour only to a condenser channel (Figure 1).

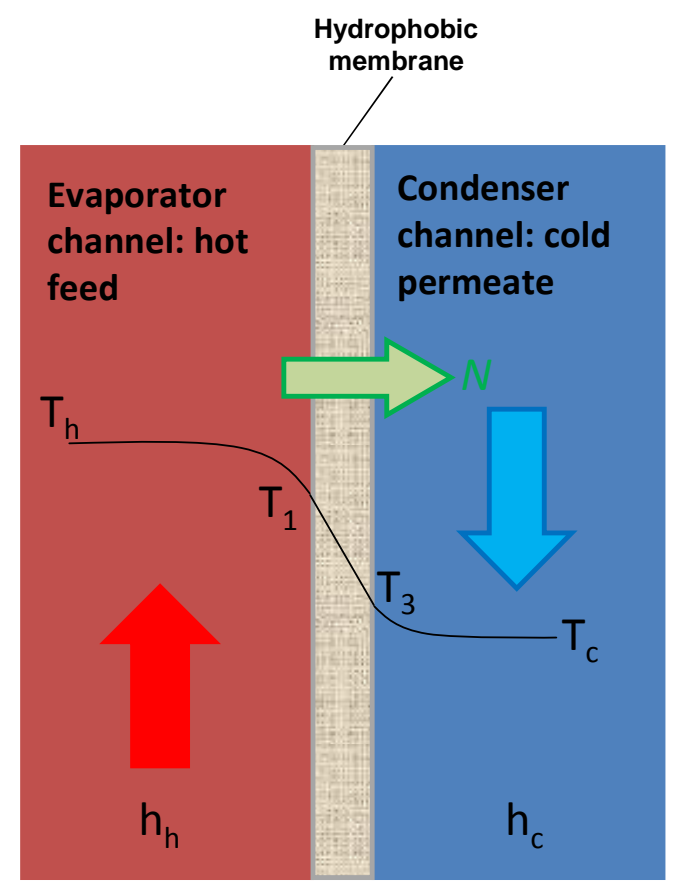

Figure 1. Operating principle of the Membrane Distillation separation process in the Direct Contact configuration (DCMD)

The driving force of the overall process is the trans-membrane vapour pressure difference, function of the liquid temperature at the two membrane interfaces, while the associated flux depends both on trans-membrane resistance to mass/heat transfer and on the convective resistance from the liquid bulk to the membrane interface on either side. The latter gives rise to the so called polarization phenomenon occurring within the liquid-filled channels. A number of published papers have already addressed the problem of a detailed mathematical description of mass and heat balance and transport equations in MD modules [8,9]. 
Polarization phenomena may play a fundamental role in controlling mass and heat transfer, thus affecting the process performance in terms of specific flux per unit surface of membrane. Polarization is also strictly related to the values of the flux crossing the membrane (the higher the flux, the larger the corresponding polarization). Thus, while most researchers are mainly working on the development of improved membranes for $\mathrm{MD}$, the problem of temperature polarization may become the dominant factor limiting flux enhancement, thus hindering the above efforts.

One of the main solutions proposed to the problem of polarization in membrane-based systems is the promotion of mixing inside the channels by a suitable choice of the module geometry. Indeed, hydrodynamics is known to play a crucial role in influencing MD module performance [10]. In this regard, spacers are normally interposed between consecutive membrane sheets in planar or spiralwound modules to mechanically support the membranes; such spacers are also beneficial as mixing promoters. The benefit of different spacer geometries in reducing polarization phenomena, thus enhancing the overall performance of the process, may be significant [11]. On the other hand, the presence of a spacer may significantly influence the fluid flow also in terms of pressure drops and shear stresses as demonstrated by a number of published studies [12-16]. Spacers so far adopted for MD applications are basically nets consisting of two or more layers of polymeric wires, which are often thought of and designed for completely different applications than MD separation. In this regard a suitable optimization of their features and geometrical configuration would be desirable to enhance the process performance.

Since mixing enhancement depends, in general, on all the geometrical features of a spacer, the effect of using different types of spacers in MD channels has been studied in order to find the geometric characteristics which maximize the heat transfer coefficient and the corresponding mass flux across the membrane, i.e. minimize the temperature polarization effect [17-21].

Spacers can be characterized by wire diameter, distance between subsequent wires, angle between wires, wire orientation with respect to the flow, etc.. In particular, the last feature is known to be one of the most important, as it is responsible for the changes in flow direction and flow pattern [22,23]. Recently Shakaib et al. (2012) [24] employed Computational Fluid Dynamics 
(CFD) to address this issue and confirmed that spacer orientation greatly affects temperature polarization and heat transfer rates.

Phattaranawik et al. [25] measured 30-40\% enhancements in mass flux across the membrane in DCMD when the channel was filled with a spacer with respect to the values obtained with an empty channel. This occurrence was also associated with a substantial increase of the temperature polarization coefficient $\tau$, defined as the ratio between the trans-membrane temperature difference and the difference between bulk temperatures in the two channels: with reference to Figure 1

$$
\tau=\left(T_{1}-T_{3}\right) /\left(T_{h}-T_{c}\right)
$$

According to this definition, the lower the value of $\tau$, the stronger is the effect of temperature polarization on the driving force, thus worsening the performance of the separation process. A coefficient ranging from 0.57 to 0.76 was found for the case of an empty channel, against values ranging from 0.9 to 0.97 in spacer-filled channels (at the same mass flow rate).

Martìnez and Rodrìguez-Maroto [26] demonstrated how the presence of a spacer significantly increases not only the heat transfer coefficient but also its dependence on the fluid flow velocity inside the channel.

Chernyshov et al. [27] carried out experiments on temperature polarization in Air Gap Membrane Distillation (AGMD) module with the aim of investigating the dependence of permeate flux and pressure drop on flow rate for five spacers of the same thickness but different geometries. They obtained fluxes up to 2.5 times higher in spacer-filled channels than that in an empty channel, thus concluding that employing an empty channel is an unacceptable choice.

Lower enhancements of the permeate flux (up to 30\%) were obtained by Yun et al. [28] for the case of DCMD modules. They also found that the effect of a spacer placed in the hot-side channel was larger than that of the same spacer placed on the cold-side.

It should be observed that the beneficial effect of the spacer on the overall performance decreases at high flow rates, when mixing is already promoted by turbulence in the fluid. In this regard, the 
findings by Phattaranawik et al. [29] suggest the existence of transitional fluid flow within the spacer-filled channels at typical MD operating conditions.

Another important aspect is the spatial resolution of the experimental techniques adopted so far. Up to now, most studies have focused on the evaluation of efficiency enhancement at a large scale by referring only to average values of temperature and heat or mass flux. Surprisingly, only little attention has been devoted to the local characterization of the spacer influence on the separation process. Data on temperature distributions would allow a better understanding of temperature polarization phenomena as related to the spacer's geometry, thus guiding the choice of the more effective spacer-channel configurations. CFD may greatly aid the design of improved spacers for MD processes: a CFD model may intrinsically be able to provide local information on temperature distribution and polarization as well as on flow field and pressure drops with any level of detail. Thus, many efforts have been devoted to the CFD simulation of spacer-filled channel modules for MD [20,21,24,30,31], but the results obtained have not yet been sufficiently validated because of the lack of detailed experimental information on local temperature and heat transfer coefficient distributions [32].

This issue is addressed in this work by employing a novel space-resolved technique, briefly presented in two previous conference papers [33-34] by the same authors, to assess the local temperature and heat transfer coefficient distribution on the membrane surface. This technique, named TLC-IA-TP, makes a combined use of Thermochromic Liquid Crystals and digital Image Analysis.

TLCs are organic compounds able to change their colour with varying temperature. They show a temperature range in which they reflect light in the visible spectrum from red (at lower temperature) through orange, yellow and green with increasing temperature, up to blue and violet (at the higher temperature). They are colourless below and above this active range of temperature [35]. TLCs are used in a number of applications, well documented in the scientific literature, for obtaining superficial temperature distributions in the study of heat transfer phenomena [36-39] and for flow dynamics visualization inside channels [40-42]. 


\section{EXPERIMENTAL SET-UP AND PROCEDURES}

\subsection{Description of the experimental facility}

A test rig was purposely designed and manufactured with the aim of measuring the temperature distribution at the hot fluid/surface interface of an "MD-like" spacer-filled channel by the use of Thermochromic Liquid Crystals in sheet form. The test section (Figure 2) consists of two channels made of Plexiglas ${ }^{\circledR}(20 \mathrm{~mm}$ thick) separated by a transparent polycarbonate layer, $1 \mathrm{~mm}$ thick, allowing heat transfer from the hot to the cold channel (thus simulating the presence of an MD membrane).

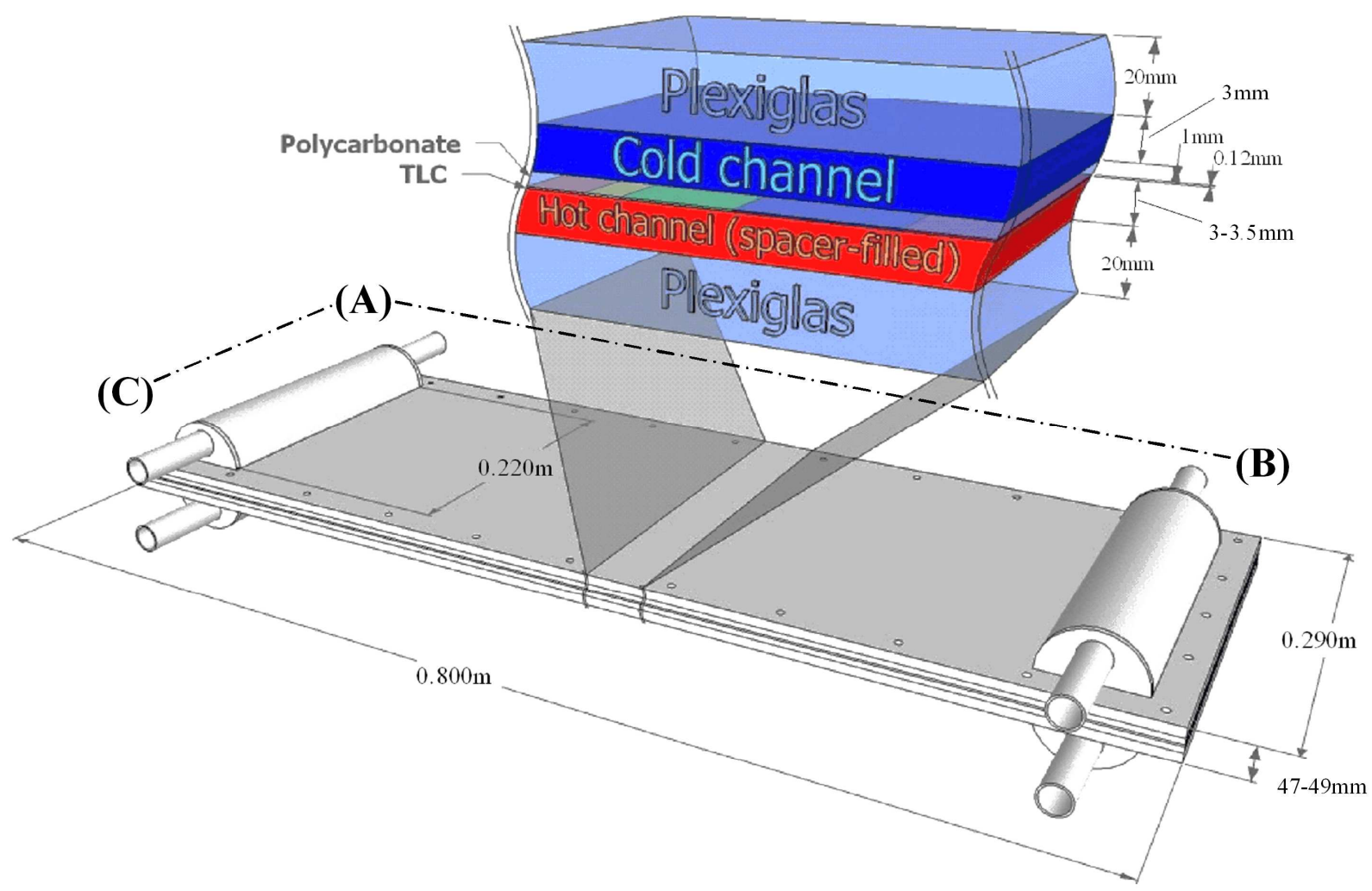

Figure 2. Representation of the test section with an enhanced detail of the different layers. Axis A-B and A-C represent the rotational axis around which the test-rig can be tilted

A schematic representation of the test section along with the temperature profile is reported in Figure 3. As a difference from Figure 1, the temperatures $T_{1}, T_{2}$ on both sides of the TLC sheet have 
been reported and the flow is assumed to be co-current as in the experimental rig standard operation.

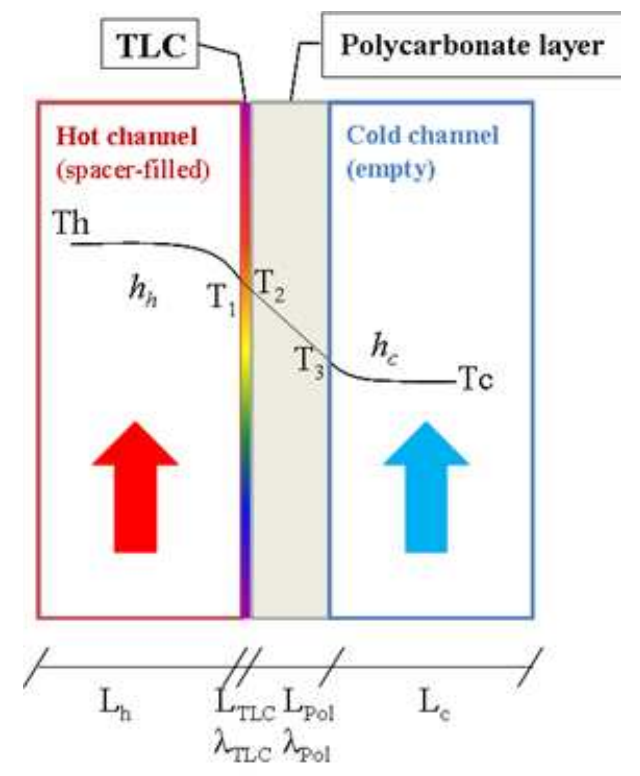

Figure 3. Sketch of the temperature profile in the test section

With reference to Figure 2 and Figure 3 the operation of the test rig is quite simple. Hot fluid is forced to flow through the "hot channel", filled with a spacer and delimited on one side by a thick and insulated Plexiglas ${ }^{\circledR}$ wall and on the other side by the polycarbonate layer. A sheet of thermochromic liquid crystals (in the present experiments Hallcrest ${ }^{\circledR}$ R30C5W were used) is interposed between this latter and the hot fluid, with the visible surface perfectly adhering to the transparent polycarbonate wall by means of a very thin layer of transparent silicon grease.

The thickness of the polycarbonate layer $L_{p o l}$ was chosen (as better illustrated in section 3.1 ) in order to maximize the wall temperature variation measured by the TLCs.

Cold fluid is forced to flow on the opposite side of the polycarbonate layer, within the "cold channel". In this latter a $3 \mathrm{~mm}$ thick, $20 \mathrm{~mm}$ wide spacer frame was also inserted to guarantee the channel thickness during the test runs and to promote turbulence in the cold fluid, but leaving the central part of the cold channel completely free for visual investigation and for recording the TLC images by a digital camera (Figure 4). Polarization phenomena occurring in the hot channel are thus 
measurable by the temperature distribution provided by the coloured TLC sheet, according to a post-processing procedure that will be described in section 2.2.

It is worth noting that, though no membrane is employed in the system, latent and conductive heat transfer through the membrane were replaced here by the conductive heat transfer from the hot channel to the cold one via conduction across the TLC and polycarbonate layers. All operating conditions have been selected in order to maximize the reliability of the experimental technique, being also within the range of typical operating conditions of MD systems. Of course, results cannot be looked as real measurements of temperature distribution within a membrane distillation unit, but can be very effectively employed to compare different spacer-filled channel configurations aiming at finding the more efficient ones and to validate advanced modelling approaches so far developed and presented in the literature $[20,21,23,24,31]$.

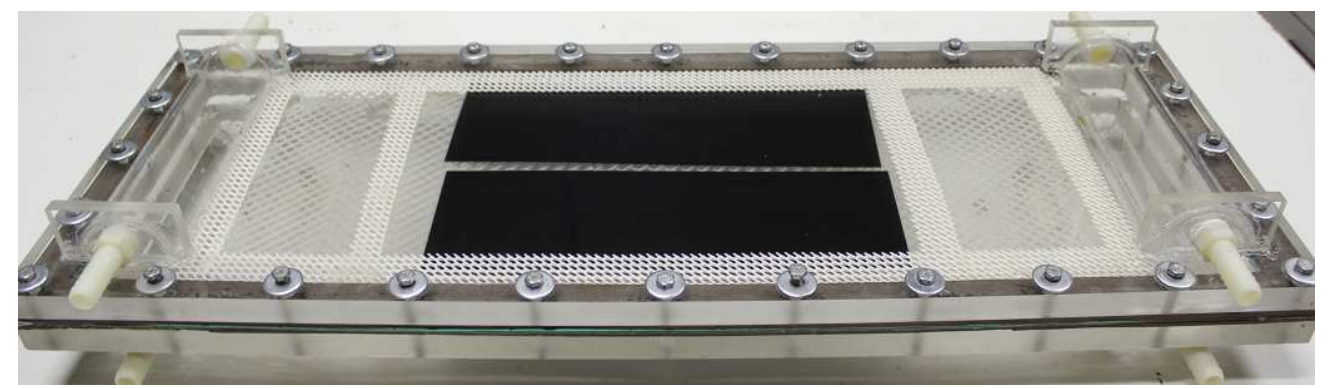

Figure 4. A picture of the test section taken from the cold channel side. The spacer frame and the black TLC sheets are visible in the upper part of the module. 


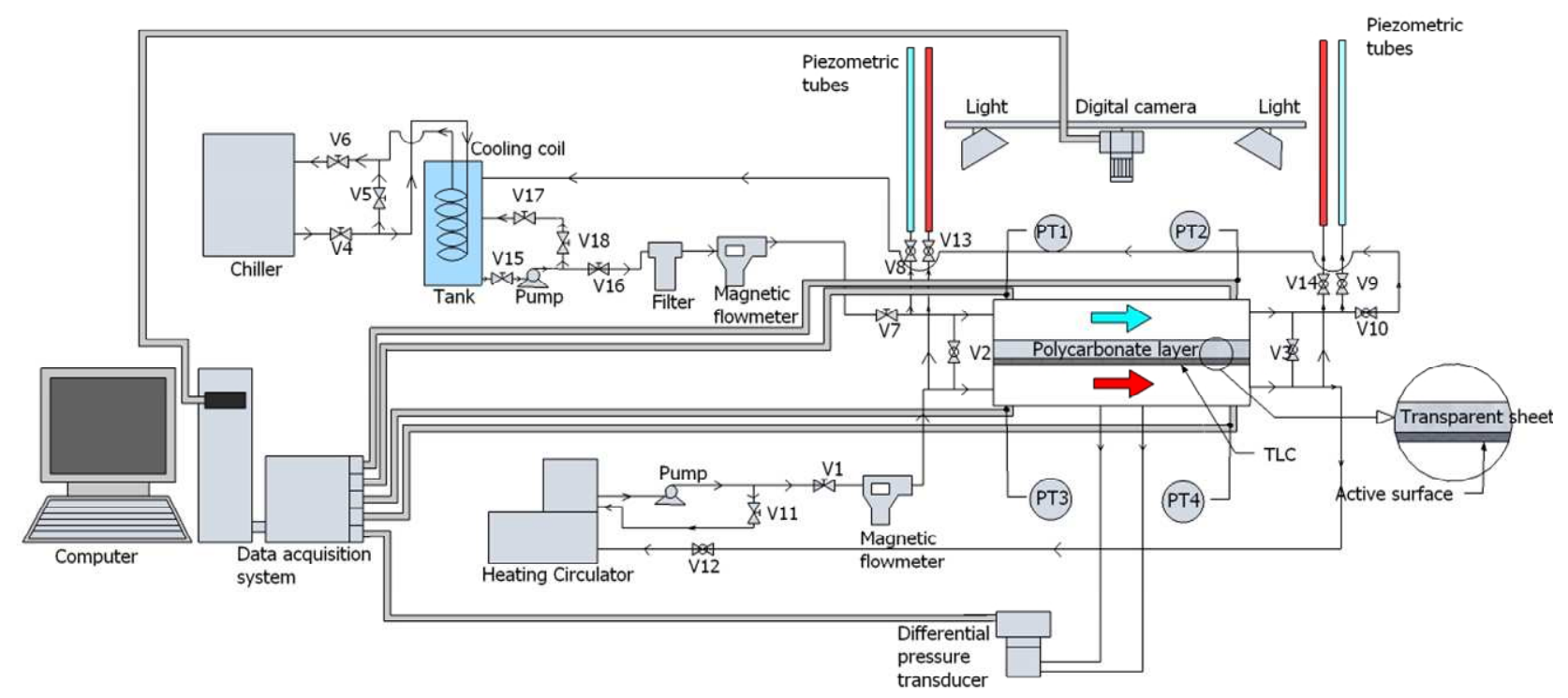

Figure 5. Schematic diagram of the experimental rig, including measuring and data acquisition equipment.

The overall scheme of the experimental rig is shown in Figure 5. The hot stream is heated by a heating circulator Julabo ${ }^{\circledR}$ ED-5, while the cold fluid is cooled by an industrial refrigerator Corema $^{\circledR}$ Junior Chiller JA/C 150, equipped with a circulator, via an interposed buffer tank provided with a cooling coil. The flow rates of hot and cold streams are controlled by by-pass circuits and globe valves, and are measured by electro-magnetic flowmeters Krohne ${ }^{\circledR}$ Optiflux 5300C. The inlet and outlet temperatures of the two liquid streams were measured by four Pt100 RTDs connected, through a signal amplifier, to a National Instruments ${ }^{\circledR}$ data acquisition board. As it can be seen in Figure 6, the whole test section is mounted on a tilting table, which allows it to rotate around the axis A-B of Figure 2 and thus to operate either in the horizontal or in the vertical orientation of the channels. An independent, orthogonal tilt (around axis A-C of Figure 2) is also possible and is used to facilitate the elimination of air bubbles during the channel fill-up process. 

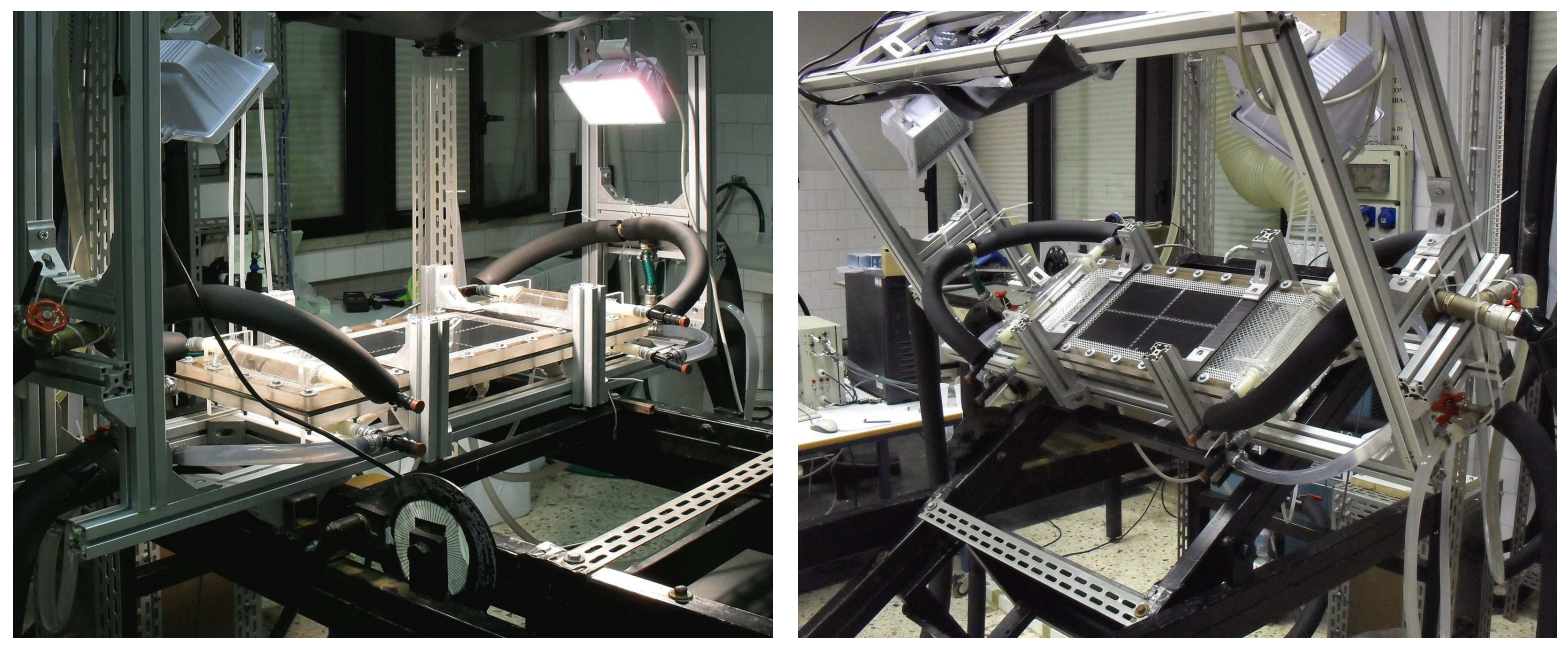

Figure 6. Pictures of the experimental rig

The TLC surface, illuminated by two halogen bulbs, was photographed by a Canon ${ }^{\circledR}$ EOS $550 \mathrm{D}$ digital camera with 18 Mpixel resolution. Several images were typically recorded at a few seconds' intervals for each experimental condition, in order to perform a statistical average of the temperature distribution maps. Results were found to be practically independent of the number of collected images, with the average maps very similar to the individual ones. Digital images were post-processed by using the Matlab Image Processing Toolbox ${ }^{\circledR}$, as described in the next section 2.2.

\subsection{TLC-IA-TP technique fundamentals}

In order to avoid image compression effects, all images were recorded in RAW form. RAW files were subsequently converted to TIFF and then split into HSV (Hue, Saturation, Value) components (Figure 7). This is necessary as original TIFF images are defined in the RGB space where the colour of each pixel results from the combination of the three intensities of red, green and blue additive primaries. On the other hand, the H component of the HSV space is close to the colour perceived by the human eye, and can be related to the corresponding temperature value in a unique way by means of a calibration curve derived in situ (see section 2.4). 


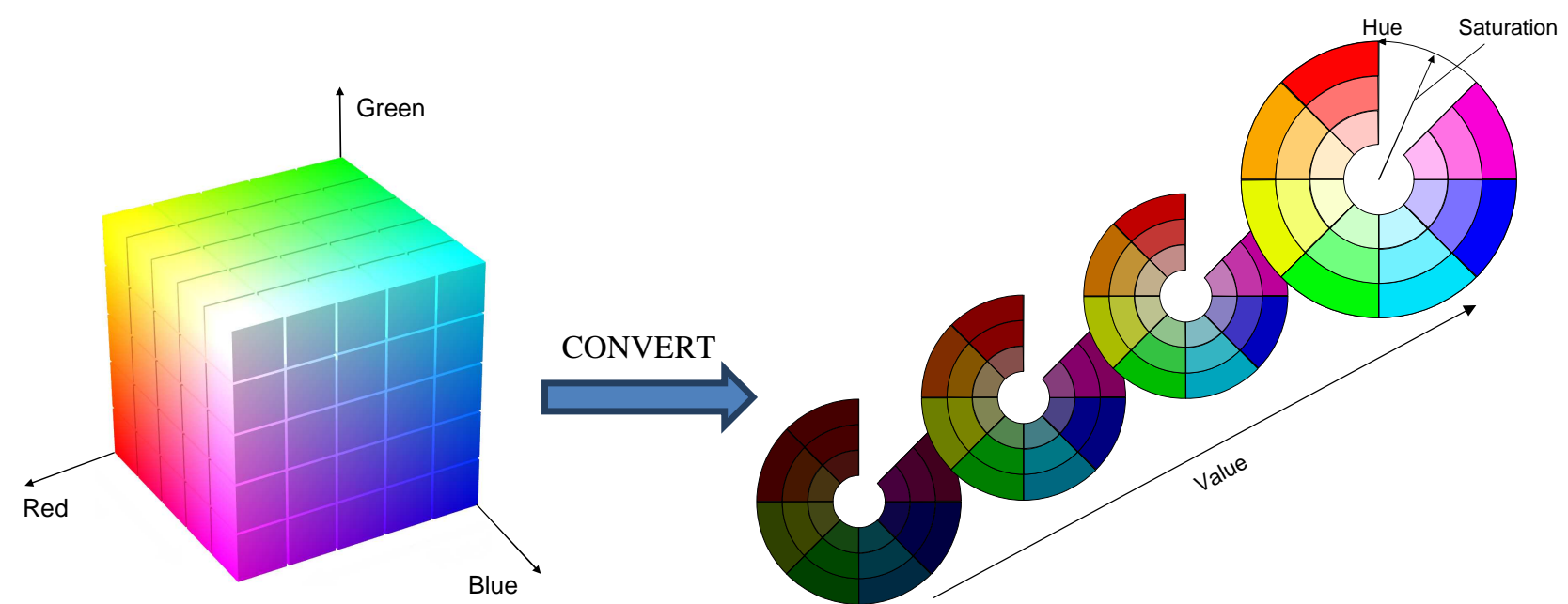

Figure 7. RGB (left) and HSV (right) colour space representations.

The colour map shown by the TLC sheet is thus converted into a map of local temperature.

With reference to the temperature profiles sketched in Figure 3 and under the assumption of onedimensional heat transfer (see section 3.2), it is possible to write the heat transfer equations in each layer of the test section, i.e. convective heat transfer in the hot channel (Eq. 2), conductive heat transfer in the TLC sheet (Eq. 3) and in the polycarbonate layer (Eq. 4), convective heat transfer in the cold channel (Eq. 5):

$$
\begin{aligned}
& q=h_{h}\left(T_{h}-T_{1}\right) \\
& q=\frac{\lambda_{T L C}}{L_{T L C}}\left(T_{1}-T_{2}\right) \\
& q=\frac{\lambda_{p o l}}{L_{p o l}}\left(T_{2}-T_{3}\right) \\
& q=h_{c}\left(T_{3}-T_{c}\right)
\end{aligned}
$$

Conventionally, the temperature exhibited by the TLCs will be identified with $T_{1}$ as justified by the structure of the TLC package, see also section 3.4. By arranging together equations $2-5$, the global heat transfer equation can be derived: 


$$
q=\frac{1}{\frac{1}{h_{h}}+\frac{L_{T L C}}{\lambda_{T L C}}+\frac{L_{p o l}}{\lambda_{p o l}}+\frac{1}{h_{c}}}\left(T_{h}-T_{c}\right)
$$

Finally the combination of Eq. 2 and Eq. 6 gives the local hot-side heat transfer coefficient $h_{h}$, which is only a function of the locally measured temperature $T_{l}$ of the TLC sheet once the bulk temperatures of hot and cold fluids and the cold-side heat transfer coefficient are known:

$$
h_{h}=\frac{T_{1}-T_{c}}{\left(T_{h}-T_{1}\right)\left(\frac{L_{T L C}}{\lambda_{T L C}}+\frac{L_{p o l}}{\lambda_{p o l}}+\frac{1}{h_{c}}\right)}
$$

Notably, $T_{h}$ and $T_{c}$ were measured by Pt100 RTDs only at the inlet and at the outlet of the 2 channels and a linear variation of $T_{h}$ and $T_{c}$ along the channel was assumed.

On the basis of the former equations and in accordance with Eq. 1, the local temperature polarization coefficient can be calculated as:

$$
\tau=\frac{T_{1}-T_{3}}{T_{h}-T_{c}}=\frac{T_{1}-\left(T_{c}+q / h_{c}\right)}{T_{h}-T_{c}}
$$

Post processing was conducted on the central region of the overall test section, thus avoiding border and entry effects (see Figure 8). 


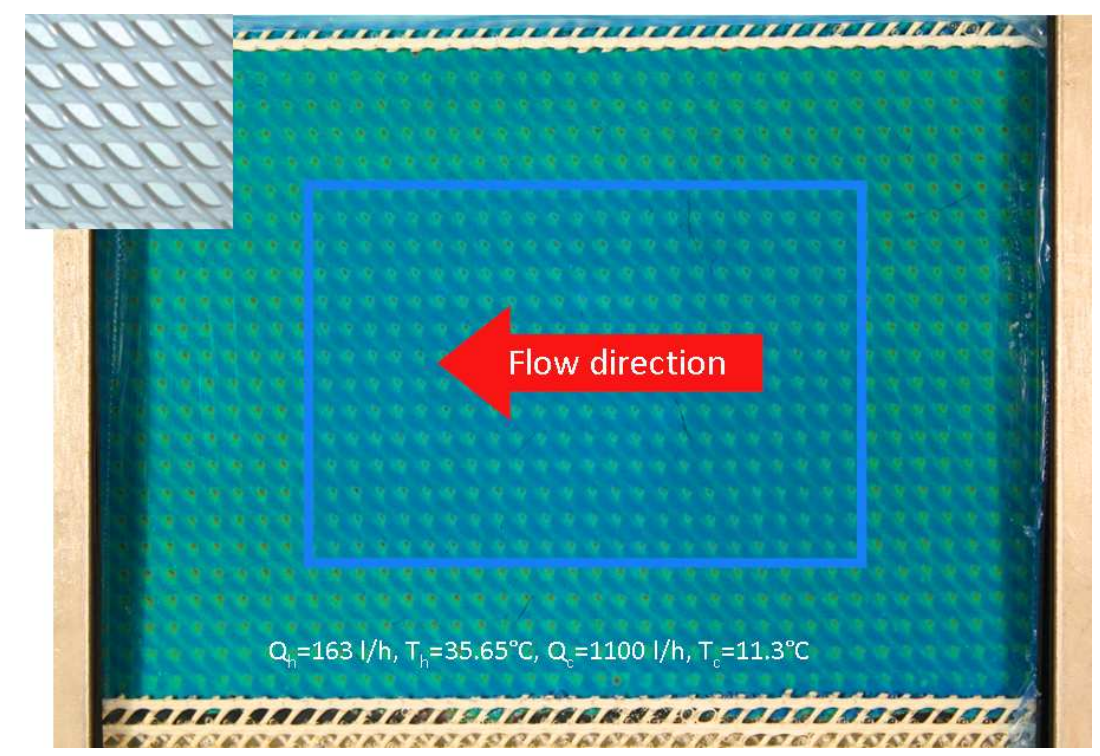

Figure 8. Illustration of the TLC surface and of the relevant investigated area for the case of Tenax-A spacer (see Table 1 and Figure 9) at $Q_{h}=163 \mathrm{l} / \mathrm{h}, T_{h}=35.65^{\circ} \mathrm{C}, Q_{c}=1100 \mathrm{l} / \mathrm{h}, T_{c}=11.3^{\circ} \mathrm{C}$.

\subsection{Spacer geometries investigated}

Experimental tests were carried out using three different spacer configurations with different geometrical features, as shown in Figure 9 and listed in Table 1. Note that the overall channel height, $h_{c h}$ may be less than the sum of the two wire diameters $d_{w 1}, d_{w 2}$ due to partial compenetration of the wires. The Tenax $\mathrm{CN}_{1} 3^{\circledR}$ spacer consists of one layer of thick wires and another layer of thinner wires oriented at $45^{\circ}$ with respect to the former. Due to its asymmetry, it was tested with either the thin wires or thick wires touching the TLC sheet, yielding the two configurations Tenax-A or Tenax-B, respectively. In both cases the thick wires were parallel to the main flow direction. Finally a symmetric commercial diamond spacer, characterized by rhombusshaped unit cells, was tested; in this case the cell diagonals were parallel to the fluid flow. 

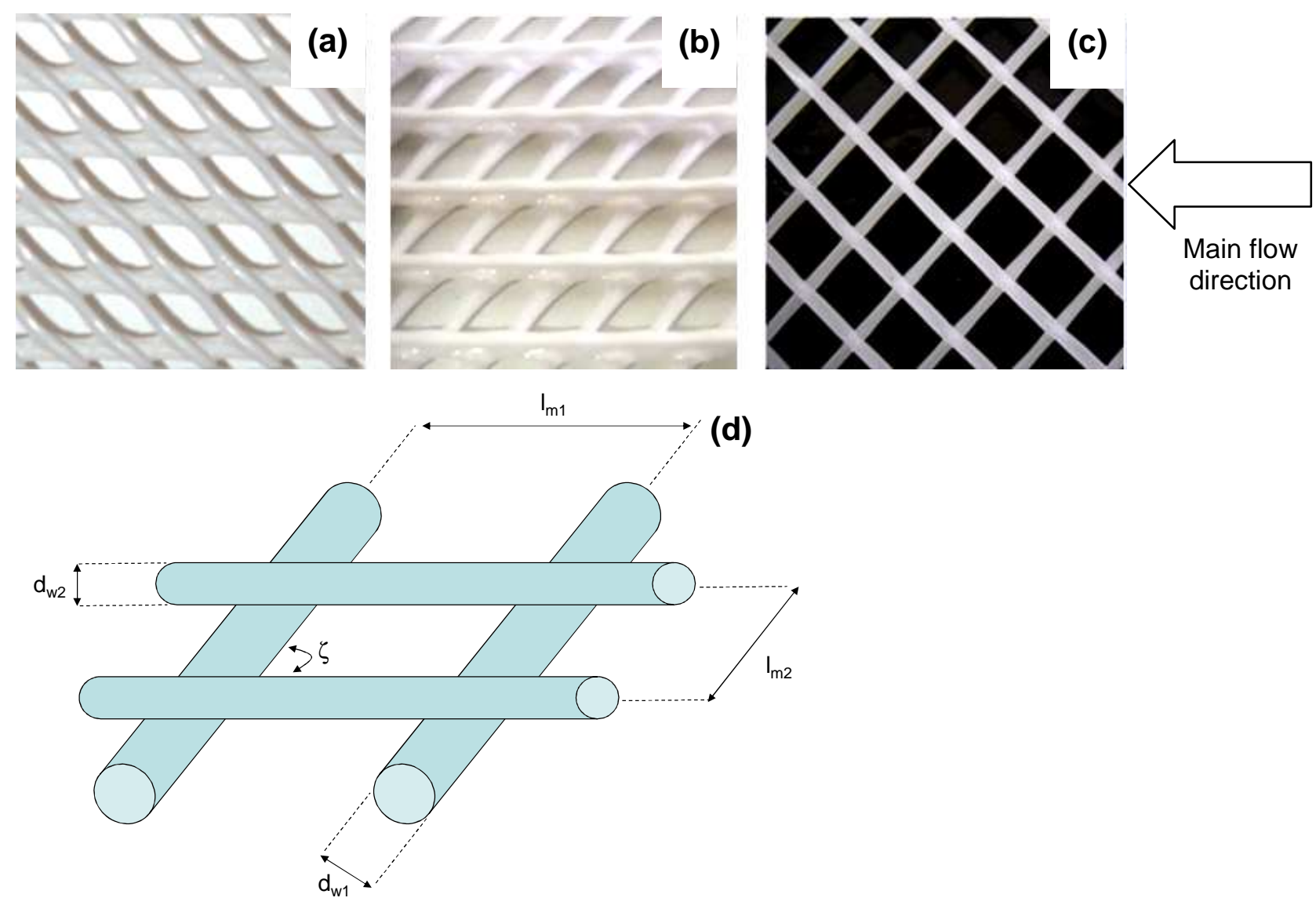

Figure 9. Pictures of the tested spacers: a) Tenax-A, b) Tenax-B, c) Diamond, d) sketch of spacer features.

For each spacer, the hot-side flow rate was made to vary from $60 \mathrm{l} / \mathrm{h}$ to $160 \mathrm{l} / \mathrm{h}$.

Table 1. List of the geometric features of the spacers tested

\begin{tabular}{|c|c|c|c|c|c|c|c|}
\hline Spacer & $\mathbf{h}_{\mathrm{ch}}[\mathrm{mm}]$ & $\zeta$ & $\mathrm{d}_{\mathrm{w} 1}[\mathrm{~mm}]$ & $\mathrm{d}_{\mathrm{w} 2}[\mathrm{~mm}]$ & $\mathbf{l}_{\mathrm{m} 1}[\mathrm{~mm}]$ & $\mathbf{l}_{\mathrm{m} 2}[\mathrm{~mm}]$ & Voidage $\varepsilon$ \\
\hline $\begin{array}{l}\left.\operatorname{Tenax}^{(}\right) \\
\text {CN13 }\end{array}$ & 3.0 & $45^{\circ}$ & 2.0 & 1.0 & 5.2 & 4.4 & 0.63 \\
\hline $\begin{array}{c}\text { Poly-net }^{\circledR} \\
\text { Type } 0128 \text { (Diamond) }\end{array}$ & 3.5 & $90^{\circ}$ & 2.0 & 2.0 & 11.0 & 11.0 & 0.85 \\
\hline
\end{tabular}

\subsection{In situ calibration of the TLCs}

The thermochromic response of the TLC sheet was first characterized by an in-situ calibration.

Water from the heating thermostat was made to circulate through the ducts on both sides of the TLC-polycarbonate wall at a temperature gradually varying from $30^{\circ} \mathrm{C}$ up to $40^{\circ} \mathrm{C}$ in $0.2^{\circ} \mathrm{C}$ steps. 
At each imposed temperature, once steady state conditions inside the test section were achieved (as indicated by the Pt100 readings), a photograph of the colorimetric response of the TLCs was acquired. This provided, after the relevant data post-processing, the Hue vs T dependence shown in Figure 10. A 6th degree polynomial was employed to fit the data within the experimentally investigated range and was adopted as the calibration curve. It is worth noting how the slope of the curve changes markedly from the green to the blue region at about $31.5^{\circ} \mathrm{C}$ and how the blue region is spread through a large range of temperatures. Experimental tests have mainly been focused on the first part of the curve, i.e. from $\sim 30^{\circ} \mathrm{C}$ up to $\sim 35^{\circ} \mathrm{C}$, where larger variations in the hue component with the temperature can be observed.

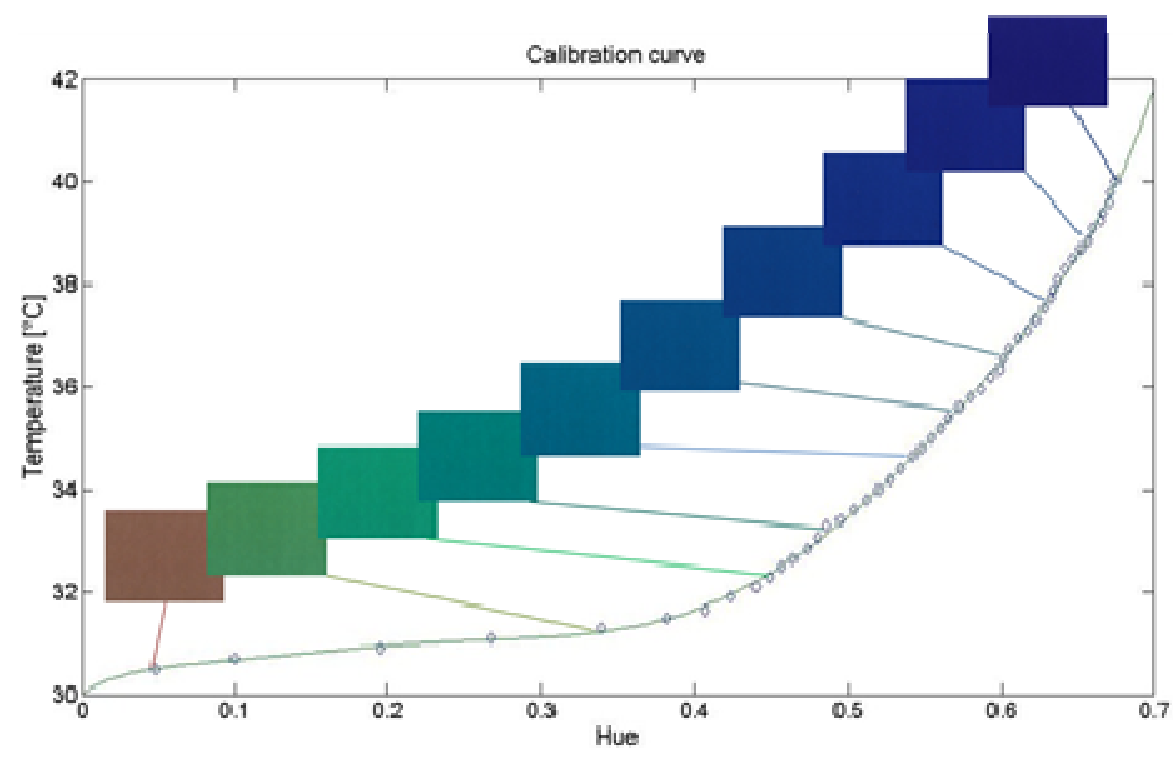

Figure 10. Calibration curve for the TLC sheet adopted during the experimental tests. Real pictures corresponding to different TLC colours corresponding to different temperatures are also shown

\section{SENSITIVITY ANALYSIS AND CHOICE OF WORKING QUANTITIES}

The set-up of the experimental technique required a careful analysis of the dependence of the results on a number of issues related to design or operating conditions and to simplifying modelling assumptions. Preliminarily, it should be observed that it is desirable to keep the hot fluid temperature as uniform as possible in the different tests, so as to obtain a fixed value of the Prandtl number thus reducing the number of parameters involved. Also, high values of $T_{h}\left(>40^{\circ} \mathrm{C}\right)$ may 
affect the TLCs' response or even damage them. The value $T_{h}=35^{\circ} \mathrm{C}$ was chosen in the present tests. In its turn, the cold fluid bulk temperature $T_{c}$ could not be reduced too much due to the limitations of the cooling system. The value $T_{c}=15^{\circ} \mathrm{C}$ was adopted here. Finally, in order to minimize thermal losses and improve the temporal stability, it is desirable that the average system temperature $\left(T_{h}+T_{c}\right) / 2$ be not too far from the ambient temperature (it was $25^{\circ} \mathrm{C}$ in the present tests).

In this section four issues are addressed, namely:

1) the choice of the polycarbonate layer thickness, $L_{p o l}$;

2) the assumption of one-dimensional heat flux;

3) the accuracy of the heat transfer coefficient estimate within the "cold channel", $h_{c}$;

4) the measurement uncertainty.

\subsection{Choice of the polycarbonate layer thickness $L_{p o l}$}

Characterizing the dependence of the $T_{1}$ temperature distribution (recorded by the TLCs) on the thickness of the polycarbonate layer, $L_{p o l}$, was an important step in the design of the test section. In fact, matching the temperature variation of the TLCs with their colour play (range of temperature in which TLCs are active) allows the resolution of the experimental information collected to be maximized.

This analysis must be based on the values of the expected heat transfer coefficient in the hot channel, $h_{h}$. In particular, the variation range of $T_{l}$ (Figure 3) corresponding to $h_{h}$ varying from a minimum $h_{h, \min }$ to a maximum $h_{h, \max }$ is a function of $L_{p o l}$ and, in some cases, attains a maximum for a specific value of $L_{p o l}$ as demonstrated in the following.

With reference to the sketch reported in Figure 3, a reduced temperature $\theta$ can be defined as:

$$
\theta=T-T_{3}
$$

Thus, Eqs. 2 to 4 can be rewritten as: 


$$
\begin{aligned}
& q=h_{h}\left(\theta_{h}-\theta_{1}\right) \\
& q=\frac{\lambda_{T L C}}{L_{T L C}}\left(\theta_{1}-\theta_{2}\right) \\
& q=\frac{\lambda_{p o l}}{L_{p o l}} \theta_{2}
\end{aligned}
$$

By combining Eqs 11 and 12:

$$
q=\frac{1}{\left(\frac{L_{T L C}}{\lambda_{T L C}}+\frac{L_{p o l}}{\lambda_{p o l}}\right)} \theta_{1}=h_{h}^{*} \theta_{1}
$$

where $h_{h}{ }^{*}$ is a fictitious heat transfer coefficient taking into account for the conduction through the TLC and polycarbonate layers. By equating Eq. 13 with Eq. 10, the relation between the temperature $\theta_{1}$ and the polycarbonate layer thickness can be obtained:

$$
\theta_{1}=\theta_{h} \frac{h_{h}}{h_{h}+h_{h}^{*}}
$$

By defining $\Delta \theta$ as the difference between the values of $\theta_{l}$ calculated for $h_{h}=h_{h, \max }$ and $h_{h}=$ $h_{h, \min }$, it is possible to analyse the trend of $\Delta \theta$ as a function of $L_{p o l}$.

This is shown in Figure 11 for $T_{h}=35^{\circ} \mathrm{C}, T_{3}=15^{\circ} \mathrm{C}, L_{T L C}=0.12 \mathrm{~mm}$ (commercial TLC sheet thickness), $\lambda_{T L C}=0.15 \mathrm{~W} / \mathrm{mK}, \lambda_{\text {pol }}=0.19 \mathrm{~W} / \mathrm{mK}, h_{h, \min }=400 \mathrm{~W} / \mathrm{m}^{2} \mathrm{~K}$ (roughly corresponding to the thermal conduction through a half channel thickness) and three different values of $h_{h, \max }(1000$, 2500 and $\left.5000 \mathrm{~W} / \mathrm{m}^{2} \mathrm{~K}\right)$. 
At $h_{h, \max }=5000 \mathrm{~W} / \mathrm{m}^{2} \mathrm{~K}, \Delta \theta$ decreases monotonically as $L_{p o l}$ increases from 0 . For $L_{p o l}=1 \mathrm{~mm}$ a value of $\Delta \theta=5.2^{\circ} \mathrm{C}$ is obtained. Such value is fairly close to the typical colour play of the TLC sheet, thus being the optimal condition for an accurate temperature measurement. When lower $h_{h, \max }$ equal to $2500 \mathrm{~W} / \mathrm{m}^{2} \mathrm{~K}$ and $1000 \mathrm{~W} / \mathrm{m}^{2} \mathrm{~K}$ are assumed, for $L_{p o l}=1 \mathrm{~mm}$ values of $\Delta \theta$ of $4.6^{\circ} \mathrm{C}$ and $3.0^{\circ} \mathrm{C}$ are estimated, respectively. These ranges of $\Delta \theta$ are still acceptable for a good resolution of the TLC temperature, although only part of the TLC colour play will be used in these cases. Thus, a value of $L_{p o l}=1 \mathrm{~mm}$ has been considered as a suitable compromise in the expected range of $h_{h}$ values. As already mentioned, it can be also observed that, for sufficiently low values of $h_{h, \max }, \Delta \theta$ exhibits a maximum at low but finite values of $L_{p o l}$.

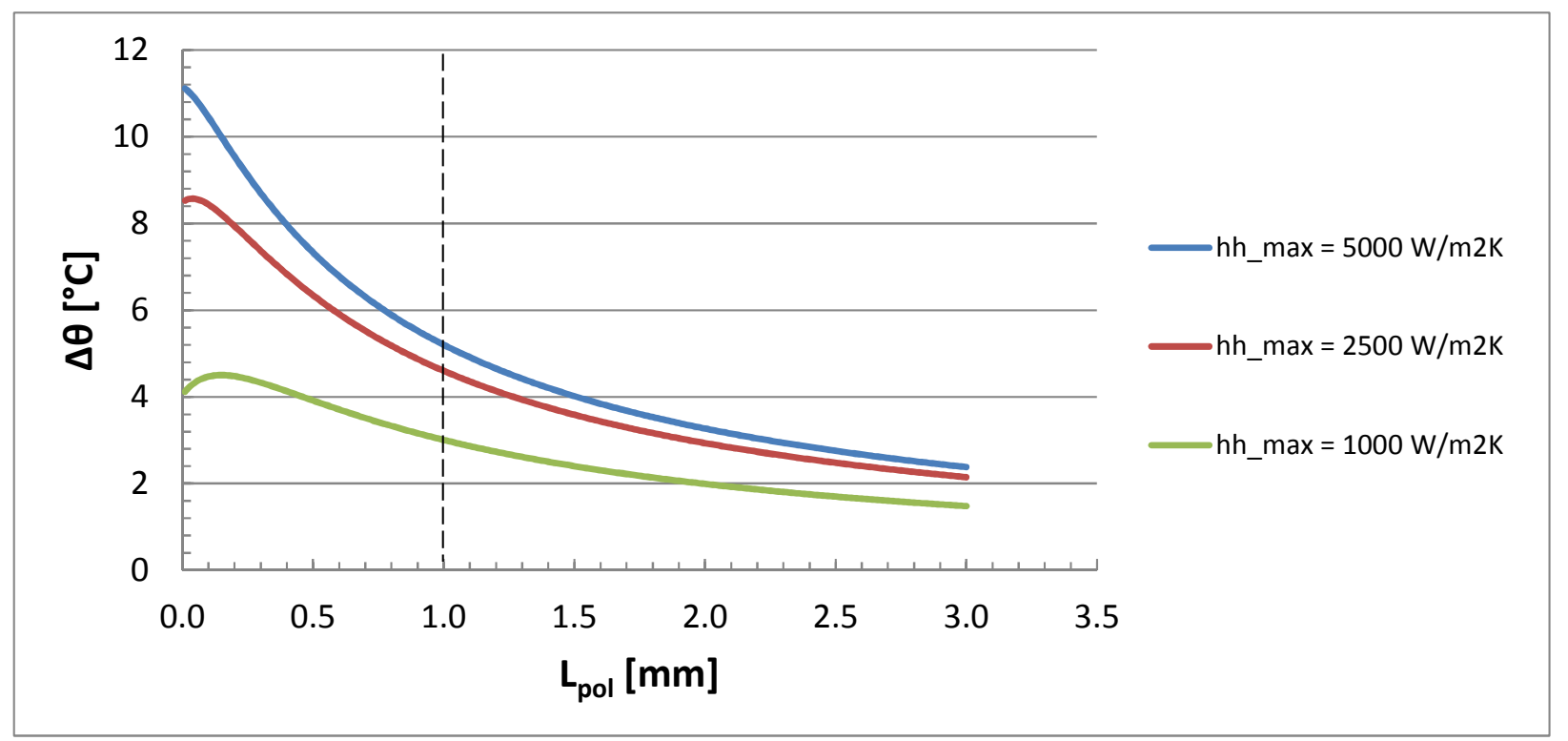

Figure 11. Variation of $\Delta \theta$ as a function of the polycarbonate layer thickness for the case of $h_{h, \max }=1000,2500,5000 \mathrm{~W} / \mathrm{m}^{2} \mathrm{~K}$, for $h_{h, \text { min }}=400 \mathrm{~W} / \mathrm{m}^{2} \mathrm{~K}, T_{h}=35^{\circ} \mathrm{C}, T_{3}=15^{\circ} \mathrm{C}, L_{T L C}=0.12 \mathrm{~mm}$ (commercial TLC sheet thickness), $\lambda_{T L C}=0.15 \mathrm{~W} / \mathrm{mK}, \lambda_{p o l}=0.19 \mathrm{~W} / \mathrm{mK}$.

\subsection{Hypothesis of one-dimensional heat flux}

Eqs. 2-5 (and 10-12) are based on the assumption of one-dimensional heat transfer, i.e. only heat flow perpendicular to the TLC-polycarbonate layer was taken into account. Actually, the presence of the spacer causes a periodic pattern of alternating zones characterized by different heat transfer coefficients and thus by different temperatures on the solid surface. These, in turn, can generate heat fluxes along directions parallel to the TLC-polycarbonate layer (longitudinal heat transfer). Since, 
the size of the spacer mesh may be comparable with the thickness of this layer, longitudinal heat transfer cannot be neglected a priori, and the one-dimensional approximation needs to be validated.

In the following, a simple theoretical analysis, based on the assumption of two-dimensional heat flux, will be conducted and the corresponding results will be compared with those obtained under the assumption of one-dimensional heat flux.

Under the hypotheses of two-dimensional heat flux, steady state conditions, absence of heat generation, constant $\lambda$ and with reference to Figure 12, the heat conduction equation can be written as:

$$
\frac{\partial^{2} T}{\partial x^{2}}+\frac{\partial^{2} T}{\partial y^{2}}=0
$$

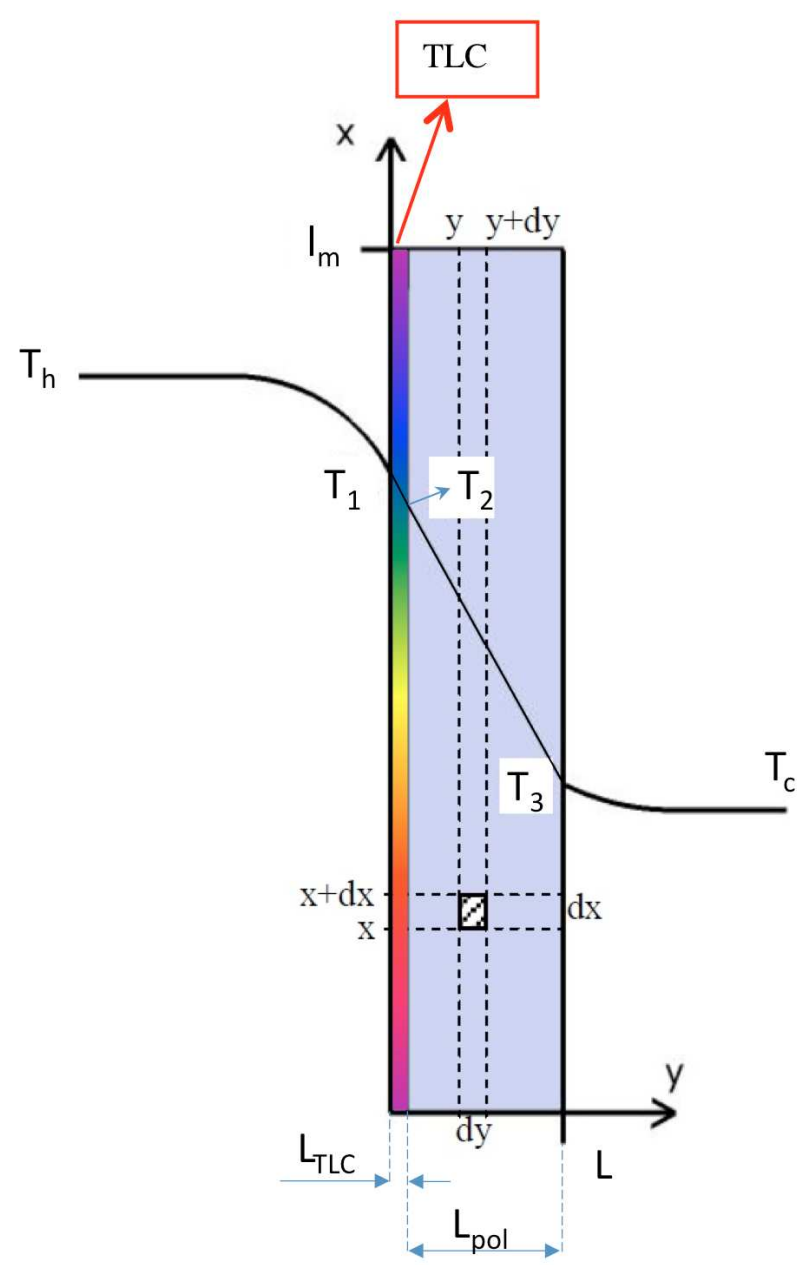

Figure 12. Sketch of the differential volume adopted to integrate equation 14. $L=L_{p o l}+L_{T L C} ; l_{m}=$ spacer pitch. 
In order to solve Eq. 15, four boundary conditions and an interface condition (between the TLC and the polycarbonate sheet) were imposed:

Heat flux continuity at the hot fluid - TLC interface:

$$
-\lambda_{T L C}\left(\frac{\partial T}{\partial y}\right)_{y=0}=h_{h}\left(T_{h}-T_{1}\right) \quad \text { for } 0 \leq \mathrm{x} \leq 1_{\mathrm{m}} ; \mathrm{y}=0
$$

Heat flux continuity at the cold fluid - polycarbonate interface:

$$
-\lambda_{p o l}\left(\frac{\partial T}{\partial y}\right)_{y=L}=h_{c}\left(T_{3}-T_{c}\right) \quad \text { for } 0 \leq \mathrm{x} \leq 1_{\mathrm{m}} ; \mathrm{y}=\mathrm{L}\left(=\mathrm{L}_{\mathrm{pol}}+\mathrm{L}_{\mathrm{TLC}}\right)
$$

Zero heat flux through the $x=0$ and $x=l_{m}$ boundaries:

$$
\begin{array}{ll}
\left(\frac{\partial T}{\partial x}\right)_{x=0}=0 & \text { for } \mathrm{x}=0 ; 0<\mathrm{y}<\mathrm{L} \\
\left(\frac{\partial T}{\partial x}\right)_{x=l_{m}}=0 & \text { for } \mathrm{x}=1_{\mathrm{m}} ; 0<\mathrm{y}<\mathrm{L}
\end{array}
$$

Heat flux continuity at the TLC-polycarbonate interface:

$$
-\lambda_{T L C}\left(\frac{\partial T}{\partial y}\right)_{y=L_{T L C}^{-}}=-\lambda_{p o l}\left(\frac{\partial T}{\partial y}\right)_{y=L_{T L C}^{+}} \quad \text { for } 0 \leq \mathrm{x} \leq 1_{\mathrm{m}} ; \mathrm{y}=\mathrm{L}_{\mathrm{TLC}}
$$

Eq. 15 along with the boundary/interface conditions in Eqs. 16-20 were implemented and solved by means of the DAEs solver of the software gPROMS $^{\circledR}[43,44]$.

A trapezoidal profile of $h_{h}$ along the $x$ direction was imposed and the corresponding profile $T_{1}$ was calculated. The $T_{1}$ profile was then employed to calculate the $h_{h}(x)$ profile via Eq. 7 valid for 
one-dimensional heat flux. Finally, the $h_{h}$ profile thus obtained was compared with the imposed one.

The results presented in Figure 13 for different values of $L=L_{p o l}+L_{T L C}$ show that the onedimensional analysis approximates quite well the profile provided by the two-dimensional one. A slight disagreement can be observed only in the zones where an abrupt jump in the $h_{h}$ spatial derivative occurs.

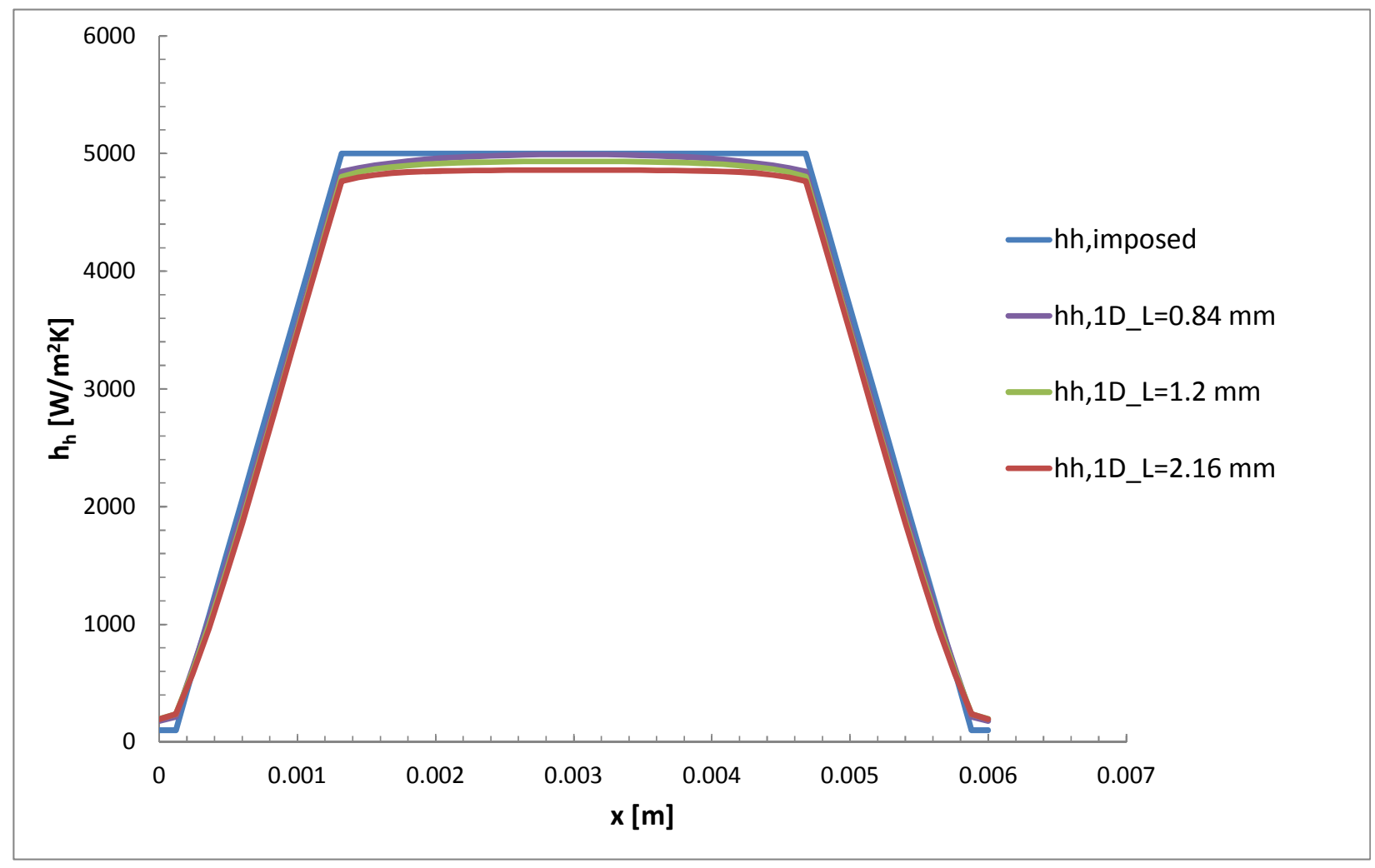

Figure 13. Comparison between the imposed $h_{h}$ trend and the corresponding calculated (according to the one-dimensional heat flux model) one for the case of $l_{m}=6 \mathrm{~mm}$.

In Figure 13 it can also be observed that the lower the thickness $L$ of the TLC-polycarbonate layer the hot and the cold channel, the lower the dicrepancy between the imposed $h_{h}$ profile and that calculated by the 1-D heat transfer hypothesis.

The effect of the spacer mesh lenght $l_{m}$ was also investigated and the relevant results are reported in Figure 14. As it can be seen, the difference between the two approaches is small and decreases as $l_{m}$ increases. 
Summarizing, it can be stated that adopting the one-dimensional approach provides a sufficiently accurate representation of the heat transport occuring in the test section.

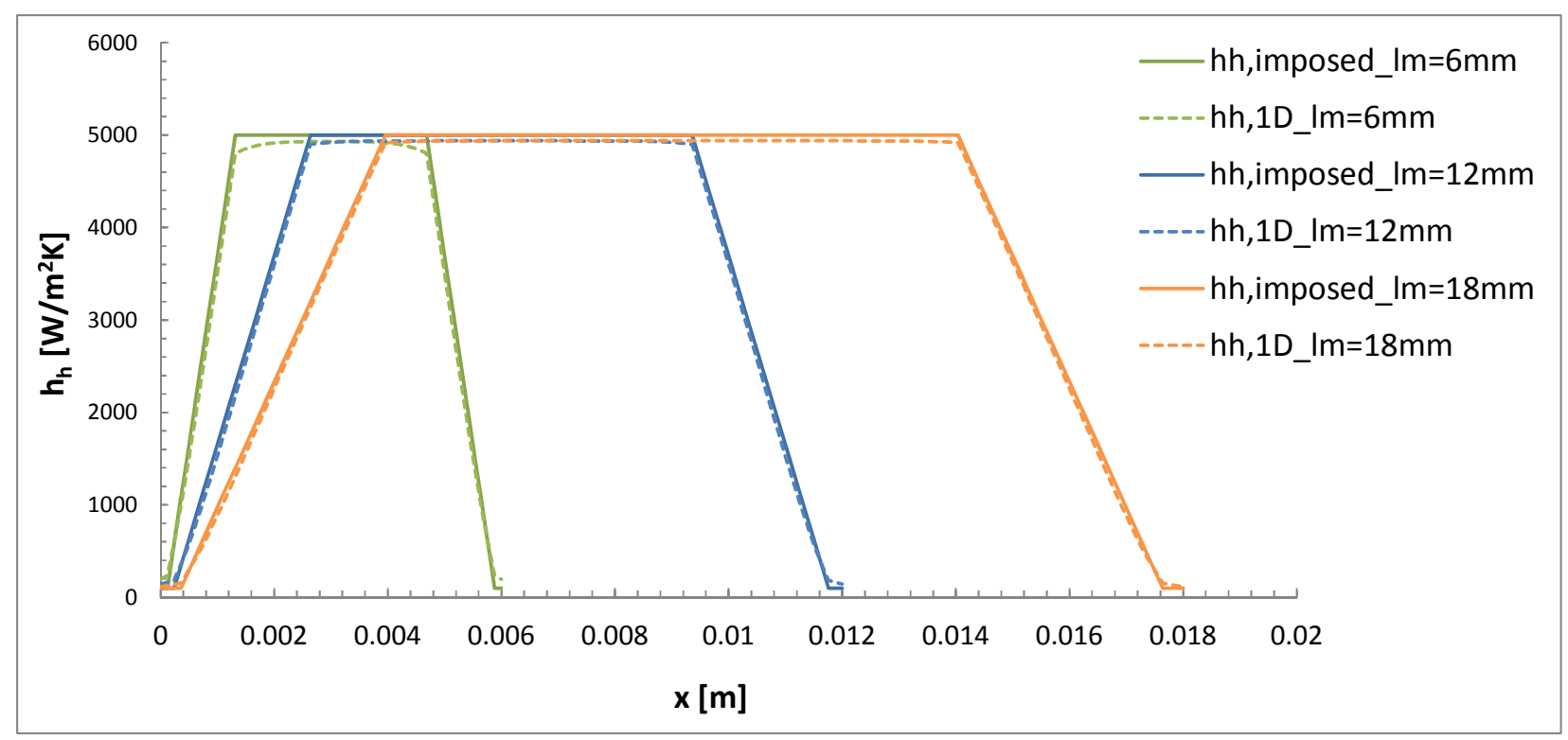

Figure 14. Comparison between the imposed $h_{h}$ trend and the corresponding calculated (according to the monodimensional heat flux model) one for the case of $L=1.2 \mathrm{~mm}$.

\subsection{Estimation of the heat transfer coefficient in the cold channel}

The heat transfer coefficient in the cold channel, $h_{c}$, was calculated via the Dittus-Boelter equation for turbulent flow in empty channels $\left(\mathrm{Nu}=0.023 \operatorname{Re}^{0.8} \mathrm{Pr}^{0.4}\right)$, although it is not strictly applicable to the present case because of the low cold-side Reynolds number $(\sim 3000)$ and of the presence of a spacer frame along the channel periphery. In order to reduce the influence of the uncertainty in $h_{c}$ on the estimate of $h_{h}$, the highest possible cold fluid flow rates were maintained during the test runs, thus achieving the highest possible values of $h_{c}$ and making the term $1 / h_{c}$ of Eq. 7 as small as possible with respect to the other ones. However, neglecting $1 / h_{c}$ altogether in Eq. 7 is not advisable and using some estimate of this quantity is preferable. A sensitivity analysis was performed by investigating the effect of a variation of $h_{c}$ on the estimated value of $h_{h}$. Even significant variations of $h_{c}$ were found to lead to very small variations of $h_{h}$ : in particular for values of $h_{c}$ ranging from 2000 to $4500 \mathrm{~W} / \mathrm{m}^{2} \mathrm{~K}$ only a difference of about $4 \%$ was found for the average $h_{h}$, thus confirming that, under the adopted operating conditions, errors in the estimate of $h_{c}$ are not 
significantly detrimental to the accuracy of the $h_{h}$ estimate. Notably, a nominal value of $h_{c} \approx 3000$ $\mathrm{W} / \mathrm{m}^{2} \mathrm{~K}$ was assumed for the uncertainty assessment presented in the following section.

\subsection{Uncertainty assessment}

A thorough assessment of the TLC-IA-TP technique uncertainty in estimating $h_{h}$ was carried out by referring to the uncertainty definition given by Moffat [45]. According to Eq. $7, h_{h}$ is depending on $n=8$ different quantities " $\mathrm{x}_{\mathrm{i}}$ ”. In formulae: $h_{h}=\mathrm{f}\left(T_{1}, T_{c}, T_{h}, L_{T L C}, \lambda_{T L C}, L_{p o l}, \lambda_{p o l}, h_{c}\right)=\mathrm{f}\left(\mathrm{x}_{1}, \mathrm{x}_{2}\right.$, $\ldots, \mathrm{x}_{\mathrm{n}}$ ). The uncertainty (standard deviation) of $h_{h}$ can be estimated as:

$$
\sigma\left(h_{h}\right)=\sqrt{\sum_{i=1}^{n}\left(\frac{\partial h_{h}}{\partial x_{i}} \sigma\left(x_{i}\right)\right)^{2}}
$$

Therefore, the assessment of the TLC-IA-TP technique uncertainty requires the knowledge of the specific uncertainties $\sigma\left(x_{i}\right)$ relevant to each of the $x_{i}$ :

$T_{1}$ ) The uncertainty relevant to the temperature of the TLC sheet comes from the calibration procedure: the conversion from Hue to temperature requires (i) the measurement of the temperature via Pt100 and (ii) the fitting of the Hue vs T points with a polynomial function. The $\sigma$ of the Pt100 adopted is $0.05^{\circ} \mathrm{C}$ (as declared by the manufacturer), while a $\sigma$ of $0.1^{\circ} \mathrm{C}$ was found for the fitting. Thus, the global $\sigma$ relevant to the variable $T_{l}$ can be conservatively estimated as $0.15^{\circ} \mathrm{C}$. The error arising by the Hue measurement via the photo-camera and the discretization error $(1 / 256)$ associated with the 1-byte representation of Hue are small and were neglected. Notably, the calibration in situ reduces further possible uncertainties in the estimate of $T_{1}$, such as those related with the spectral content of the light source.

$T_{h}, T_{c}$ ) Also the $\sigma$ relevant to these variables derive from two contributions: one is again due to the Pt100 uncertainty (i.e. $0.05^{\circ} \mathrm{C}$ ), while the other is due to the assumption of a linear variation of 
the temperature along the channel. This latter $\sigma$ was estimated to be $0.1^{\circ} \mathrm{C}$. Therefore, the global $\sigma$ relevant to the variables $T_{h}$ and $T_{c}$ has been assumed to be conservatively $\sim 0.15^{\circ} \mathrm{C}$.

$\left.L_{T L C}, L_{p o l}\right)$ For these two quantities a conservative uncertainty of $10^{-5} \mathrm{~m}$ was chosen in accordance with the maximum variability experimentally measured by a thickness gauge (Schimdt Control Instruments, resolution $\pm 1 \mu \mathrm{m}$ ) on several samples of TLC and polycarbonate.

$\left.\lambda_{\text {pol }}\right)$ On the basis of the values which can be found in different handbooks, a $\sigma\left(\lambda_{\text {pol }}\right)$ equal to $0.015 \mathrm{~W} / \mathrm{mK}$ was assumed.

$\left.\lambda_{T L C}\right)$ Since the TLCs are a composite material a $\sigma\left(\lambda_{T L C}\right)$ twice $\sigma\left(\lambda_{\text {pol }}\right)$ was chosen.

$h_{c}$ ) For the case of the heat transfer coefficient in the cold channel an uncertainty of $500 \mathrm{~W} / \mathrm{m}^{2} \mathrm{~K}$ was assumed.

The uncertainties employed for the eight quantities are summarized in the following Table 2.

Table 2: Uncertainties relevant to the quantities necessary to estimate $h_{h}$.

\begin{tabular}{|c|c|c|c|c|c|c|c|c|}
\hline Quantity & $\begin{array}{c}T_{l} \\
{\left[{ }^{\circ} \mathrm{C}\right]}\end{array}$ & $\begin{array}{c}T_{c} \\
{\left[{ }^{\circ} \mathrm{C}\right]}\end{array}$ & $\begin{array}{c}T_{h} \\
{\left[{ }^{\circ} \mathrm{C}\right]}\end{array}$ & $\begin{array}{c}L_{T L C} \\
{[\mathrm{~m}]}\end{array}$ & $\begin{array}{c}\lambda_{T L C} \\
{[\mathrm{~W} / \mathrm{mK}]}\end{array}$ & $\begin{array}{c}L_{p o l} \\
{[\mathrm{~m}]}\end{array}$ & $\begin{array}{c}\lambda_{\text {pol }} \\
{[\mathrm{W} / \mathrm{mK}]}\end{array}$ & $\begin{array}{c}h_{c} \\
{\left[\mathrm{~W} / \mathrm{m}^{2} \mathrm{~K}\right]}\end{array}$ \\
\hline Uncertainty $\sigma$ & 0.15 & 0.15 & 0.15 & 0.00001 & 0.03 & 0.00001 & 0.015 & 500 \\
\hline
\end{tabular}

By applying Eq. 21 it results that the higher the $h_{h}$, the higher the relative uncertainty $\sigma\left(h_{h}\right) / h_{h}$ as Figure 15 shows: 


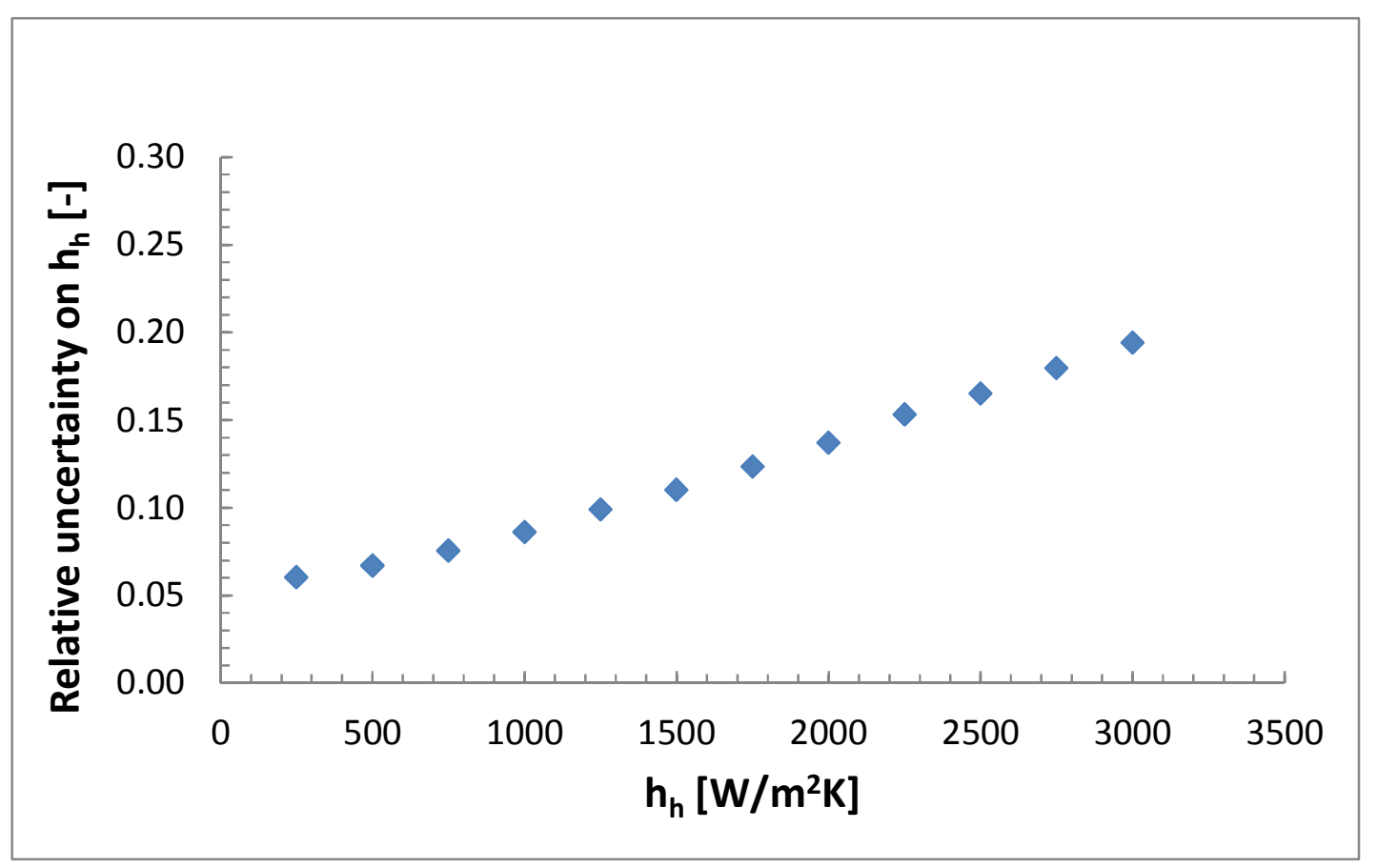

Figure 15. Uncertainty on measurement versus the corresponding $h_{h}$ values

This occurrence is due to the difference $\left(T_{h}-T_{1}\right)$ which decreases as $h_{h}$ increases. This difference significantly affects the global uncertainty since it appears in the denominator of all the partial derivatives in Eq. 21.

As concerns the mean value of $h_{h}$, the uncertainty in the measurement of this quantity was estimated to be below $\pm 15 \%$ for practically all the cases investigated in the present work. Only in the case of the diamond spacer at the highest flow rate (which leads to the highest $h_{h}$ ), a $\sigma$ of $\approx 18 \%$ was estimated. An example relevant to the Tenax-A spacer is reported in Figure 16 where the different symbols refer to two distinct tests (conducted at several days' distance) while the error bars represent the calculated $\sigma$. It is worth observing that the TLC-IA-TP technique was found to have a good reproducibility as a close inspection of Figure 16 shows: only a very slight difference in the values of $h_{h}$ between the two tests was found (maximum discrepancy below $1.2 \%$ ). 


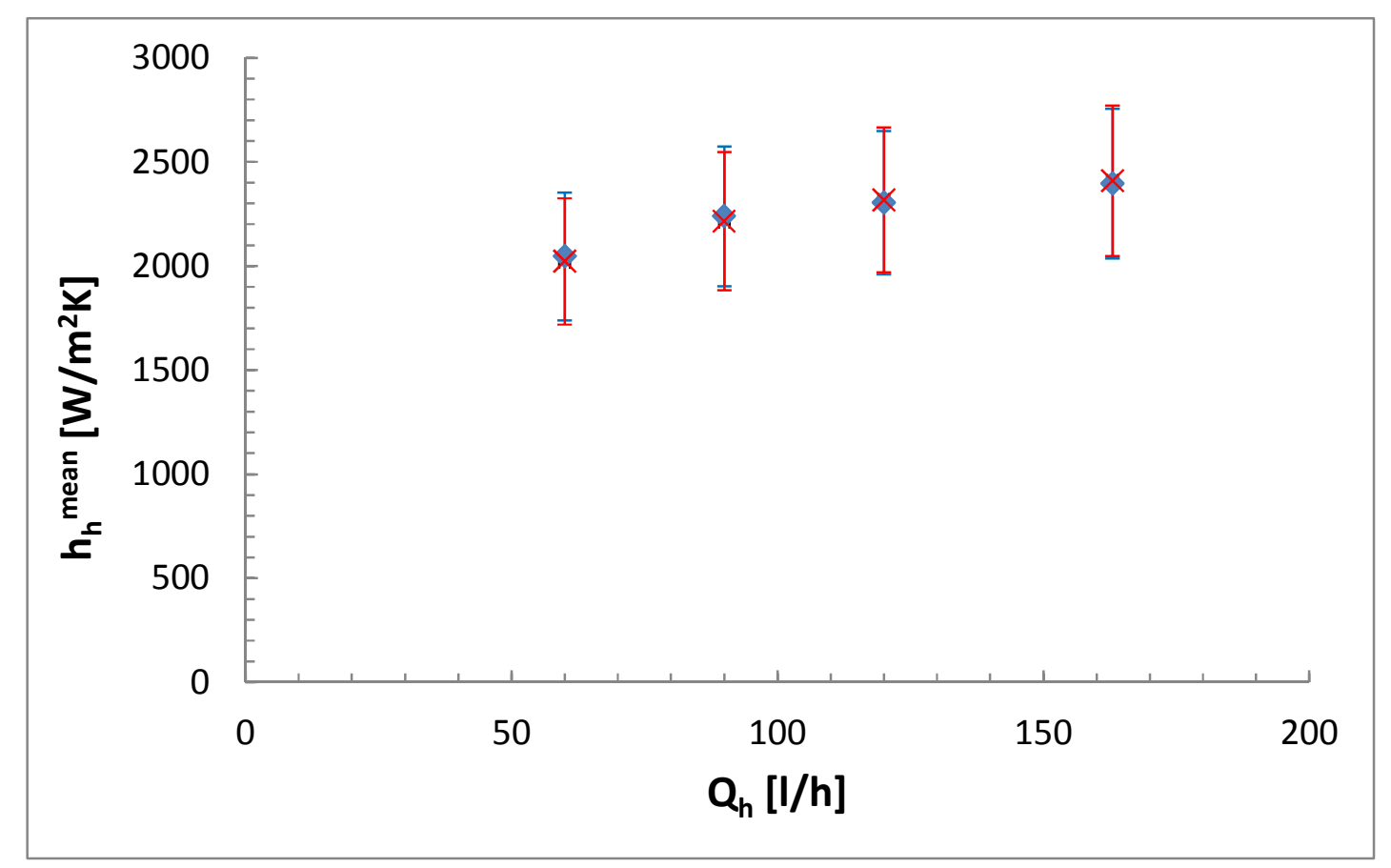

Figure 16. Trend of measured values of heat transfer coefficient for the case of the spacer Tenax-A, indicating the TLC-IA-TP technique's uncertainty and reproducibility. The two symbols refer to a set of experiments and the relevant reproducibility test performed, respectively.

A further analysis was carried out aiming at finding the quantities whose uncertainty mostly affects $\sigma\left(h_{h}\right)$. Figure 17 reports the relative importance of the various contributions to the total uncertainty $\sigma\left(h_{h}\right)$. As it can be seen, when $h_{h}$ is low, the global $\sigma\left(h_{h}\right)$ is mainly due to the polycarbonate thermal conductivity uncertainty which alone contributes about $34 \%$ of $\sigma\left(h_{h}\right)$. The other main contributions come from $\sigma\left(T_{1}\right)$ and $\sigma\left(T_{c}\right): T_{1}$ and $T_{c}$ are the only two quantities for which the term $\left(T_{h}-T_{l}\right)^{2}$ appears at the denominator in the relevant partial derivatives. This explains why their relative contribution greatly increases as $h_{h}$ increases. Conversely only a slight relative influence on $\sigma\left(h_{h}\right)$ was found for the other quantities: in particular, the results of Figure 17 confirm the small effect of the uncertainty in $h_{c}$. 


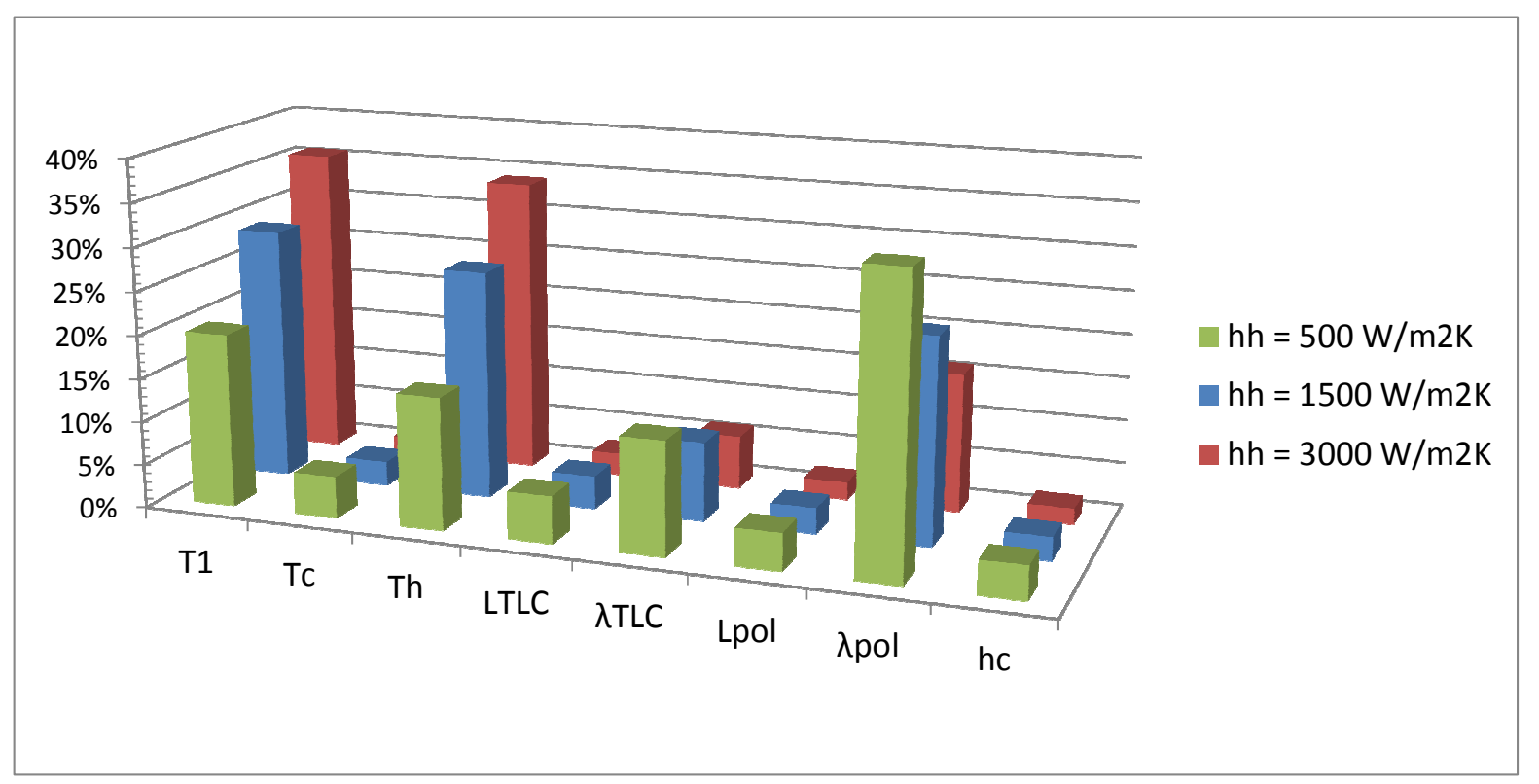

Figure 17. Influence of each $\sigma\left(x_{i}\right)$ on $\sigma\left(h_{h}\right)$ as a function of $h_{h}$. Values are normalized by the total uncertainty so that their sum is 1 .

\section{RESULTS AND DISCUSSION}

\subsection{Temperature and heat transfer coefficient distribution}

Following the formerly described procedure, the images acquired during the experimental tests were post-processed in order to obtain distributions of temperature and heat transfer coefficient.

As previously mentioned, three different spacer-channel configurations were investigated.

The results relevant to the spacer named Tenax-A are presented in Figure 18. In particular, Figure 18a reports the original photograph of a test region, which contains 9 repetitive unit cells of the spacer. Figure $18 \mathrm{~b}$ shows the relevant temperature distribution map. Figure $18 \mathrm{c}$ shows the corresponding local heat transfer coefficient. Note that, here as in the following Figure 19 Figure 19. and Figure 20, in all graphs (a,b,c) the viewing direction is from the cold channel side as in the actually recorded pictures. 

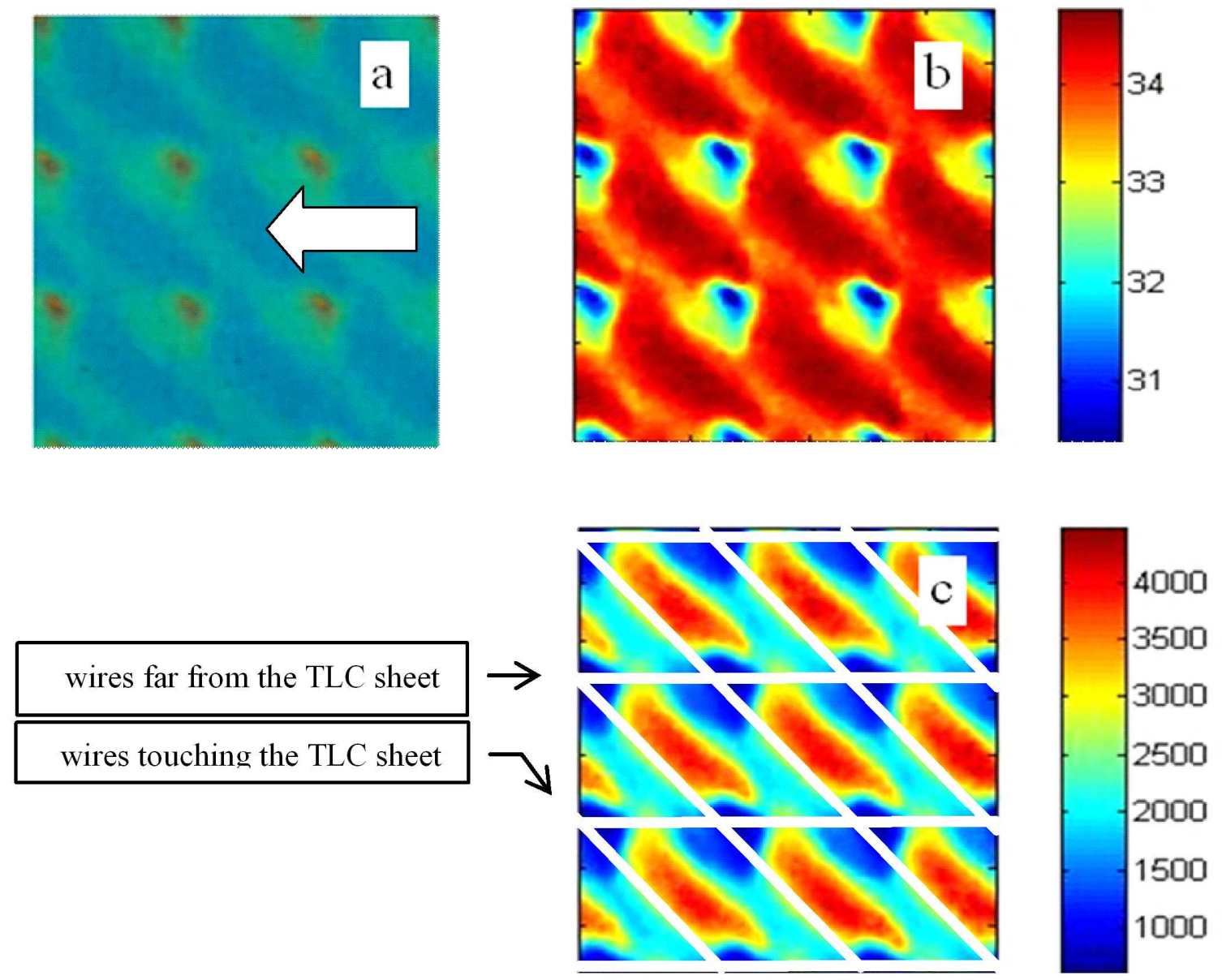

Figure 18. Images obtained with the Tenax-A spacer at $Q_{h}=1631 / \mathrm{h}, T_{h}=35.65^{\circ} \mathrm{C}, Q_{c}=1100 \mathrm{l} / \mathrm{h}, T_{c}=14.3^{\circ} \mathrm{C}$ : a) Typical test region showing the TLC surface along with an arrow indicating the main flow direction; b) Distribution of local temperature $\left[{ }^{\circ} \mathrm{C}\right]$ on the TLC surface; c) Distribution of the local hot-side heat transfer coefficient $\left[\mathrm{W} / \mathrm{m}^{2} \mathrm{~K}\right]$ along with lines showing the location of the spacer wires.

By analysing the images recorded and with reference to the actual position of the wires, reported for clarity purposes in Figure 18c, it is possible to identify in each unit cell three different regions characterized by:

- Minimum temperature and heat transfer coefficient $\left(h_{h}<1500 \mathrm{~W} / \mathrm{m}^{2} \mathrm{~K}\right.$ in Figure $\left.18 \mathrm{~d}\right)$ in correspondence with the intersection points where the thicker longitudinal wires push the thinner oblique wires tightly against the wall so that convection is inhibited and heat transfer occurs purely by conduction. In these regions, the local temperature polarization coefficient $\tau$ of Eq. 8 is $\sim 0.72$.

- High temperature and heat transfer coefficient $\left(h_{h}>3000 \mathrm{~W} / \mathrm{m}^{2} \mathrm{~K}\right.$ in Figure $\left.18 \mathrm{~d}\right)$ in the reattachment regions immediately upstream of the oblique wires, where mixing is enhanced thanks to a significant presence of velocity components perpendicular to the conductive wall, 
thus resulting in $\tau$ values close to 1 . These regions are roughly elliptic and elongated in a $45^{\circ}$ direction due to the wires' orientation.

- Intermediate temperature and heat transfer coefficient $\left(1500<h_{h}<3000 \mathrm{~W} / \mathrm{m}^{2} \mathrm{~K}\right.$ in Figure $\left.18 \mathrm{~d}\right)$ immediately downstream of the oblique wires and, particularly, downstream of contact areas, in correspondence with separated flow regions (here, $\tau \approx 0.72-0.85$ ).

It is worth noting that the heat transfer coefficient does not attain minimum (purely conductive) values along the whole linear contact between the wall and the oblique wires, presumably because these latter are rather flimsy and allow some residual flow rate.

The Tenax-B spacer is geometrically identical to the Tenax-A: the only difference concerns the orientation. In the case of Tenax-B, the longitudinal wires are in contact with the TLC surface. Relevant results are presented in Figure 19 and show surface patterns of temperature and heat transfer coefficient quite different from those observed with Tenax-A. 

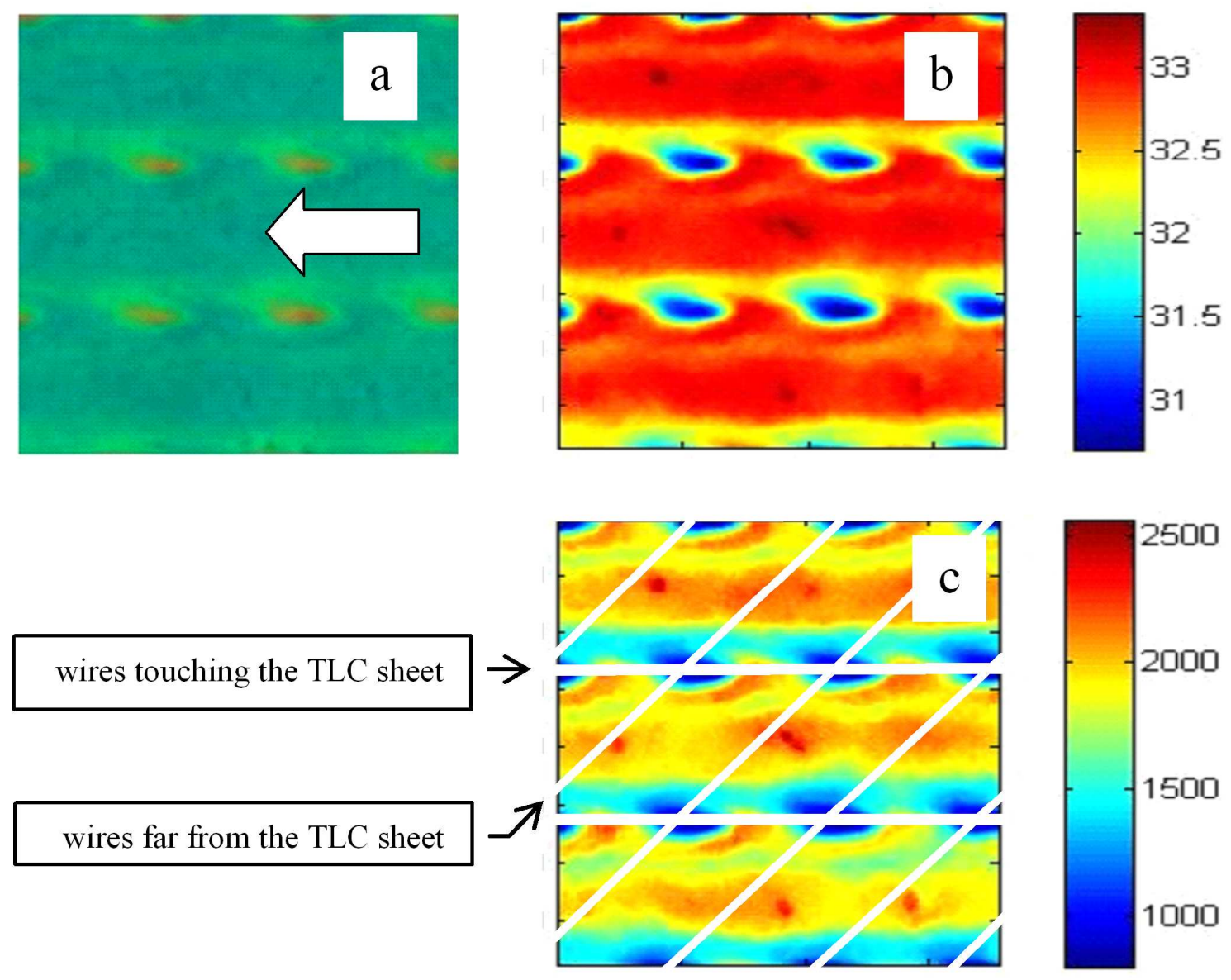

Figure 19. Images obtained with the Tenax-B spacer at $Q_{h}=1631 / \mathrm{h}, T_{h}=34.75^{\circ} \mathrm{C}, \mathrm{Q}_{\mathrm{c}}=1100 \mathrm{l} / \mathrm{h}, T_{c}=14.6^{\circ} \mathrm{C}$ : a) Typical test region showing the TLC surface along with an arrow indicating the main flow direction; b) Distribution of local temperature $\left[{ }^{\circ} \mathrm{C}\right]$ on the TLC surface; c) Distribution of the local hot-side heat transfer coefficient $\left[\mathrm{W} / \mathrm{m}^{2} \mathrm{~K}\right]$ along with lines showing the location of the spacer wires.

As also already observed in Figure 18 for the Tenax-A spacer, the lowest values of $h_{h}$ (purely conductive heat transfer) occur in the zones where the two arrays of spacer wires intersect, due to the tight contact between the wall and the near-wall wires (which in this case are the thick, longitudinal ones). The highest $h_{h}$ can be observed in the central strips between the longitudinal wires, without a clear relation with the location of the thinner oblique wires. Smaller, crescentshaped, regions of high heat transfer occur also upstream of the contact spots and downstream of the thick wires. The maximum $\tau$ exhibited by the Tenax-B configuration is equal to $\sim 0.89$ which is lower than that found for the Tenax-A configuration. 
It is worth noting how the irregular shape of filaments generates also an irregular distribution of temperatures and heat transfer coefficients, leading, for example, to a TLC-spacer contact area corresponding to the crossing of the longitudinal and oblique filaments.

A more regular geometry (and, thus, behaviour) can be observed in the Diamond spacer, in which the wires are almost perfect circular rods. Moreover, the Diamond spacer is characterized by symmetry properties thus appearing as particularly suitable for MD spiral wound modules where two membranes are simultaneously employed on the two sides of the same channel. A symmetric spacer guarantees identical mixing conditions as well as identical values of $h_{h}$. Conversely, spacers made of overlapped wires with different orientations (as the previously analyzed Tenax spacer) lead to different heat fluxes on the two sides.

As Figure 20b-c show, absolute minima of temperature $T$ and heat transfer coefficient $h_{h}$ are still recognizable in the intersection points where the contact between wires and wall is tightest, as in the previous geometries, but now continuous stripes characterized by values almost as low of $T$ and $h_{h}$ exist along the wires touching the TLC sheet. Here, these zones are much sharper than in the other spacers due to the Diamond wires being more stiff and regular. In all the other zones, large regions of high $h_{h}$ are observable suggesting that this spacer is particularly suitable to promote an efficient and uniform fluid mixing thus resulting in average $\tau$ values close to 1 . 

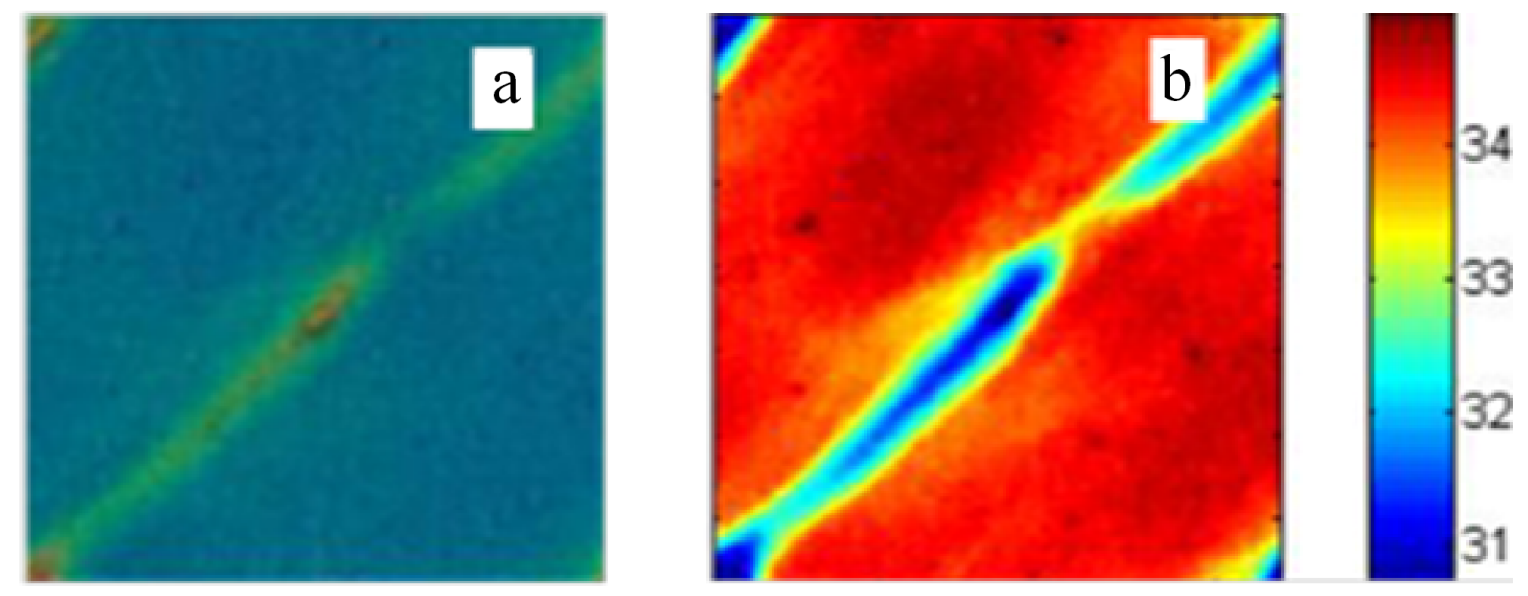

0

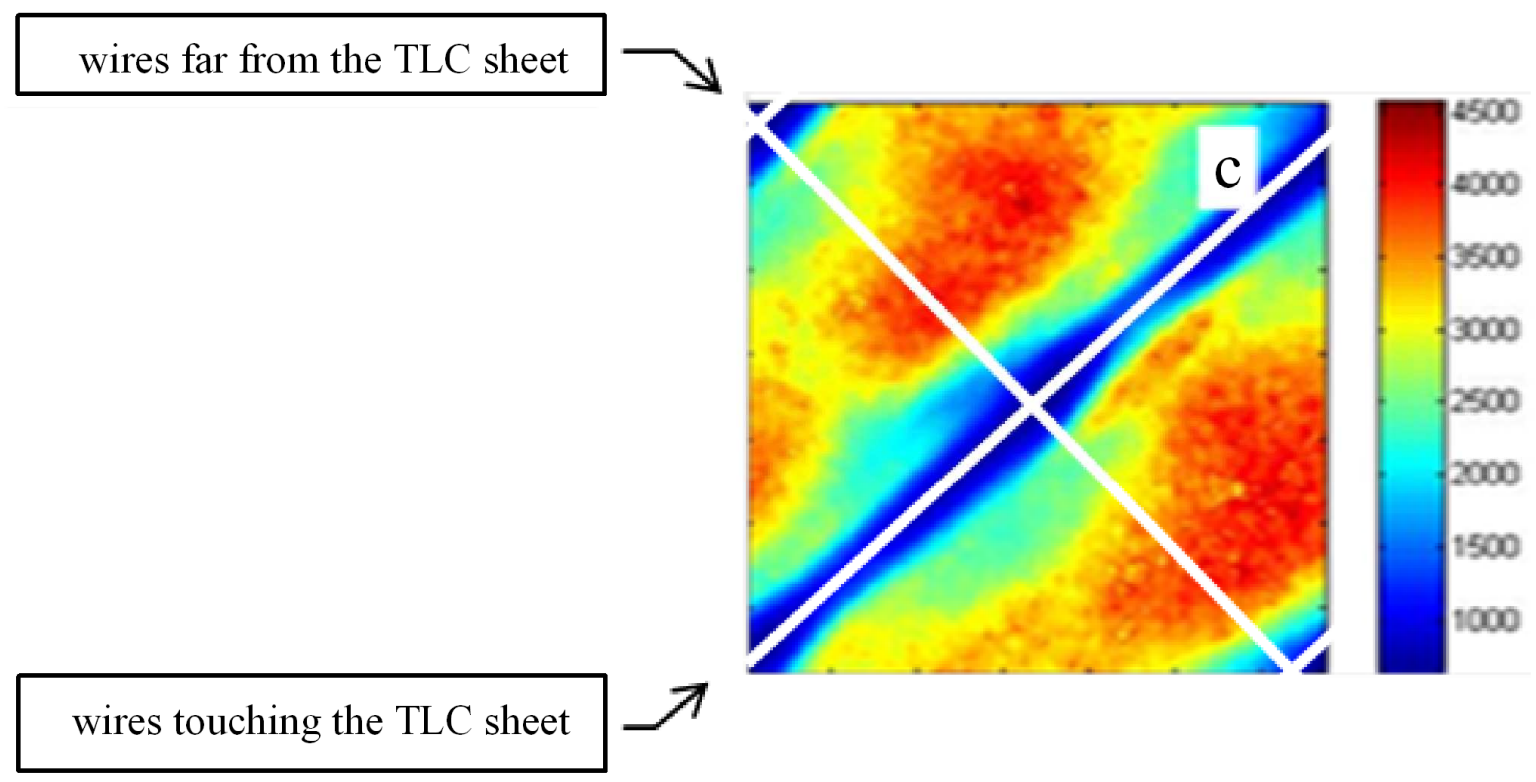

Figure 20. Images obtained with the Diamond spacer at $Q_{h}=1631 / \mathrm{h}, T_{h}=35.65^{\circ} \mathrm{C}, Q_{c}=1000 \mathrm{l} / \mathrm{h}, T_{c}=14.55^{\circ} \mathrm{C}$ : a) Typical test region showing the TLC surface along with an arrow indicating the main flow direction; b) Distribution of local temperature $\left[{ }^{\circ} \mathrm{C}\right]$ on the TLC surface; c) Distribution of the local hot-side heat transfer coefficient $\left[\mathrm{W} / \mathrm{m}^{2} \mathrm{~K}\right]$ along with lines showing the location of the spacer wires.

\subsection{Comparison between spacers}

By letting the flow rate in the hot channel vary from $60 \mathrm{l} / \mathrm{h}$ to $160 \mathrm{l} / \mathrm{h}$ and post-processing images and data for each spacer, a comparison was conducted between different spacer geometries.

Figure 21 shows how the mean heat transfer coefficient varies with the hot water flow rate $Q_{h}$ for the tested spacers. Tenax-A and Diamond, both with oblique wires close to the conductive wall, present higher $h_{h}$ in the whole $Q_{h}$ range investigated with respect to Tenax-B, thus indicating that 
oblique wires are more effective in promoting mixing inside the channel, with respect to longitudinal wires.

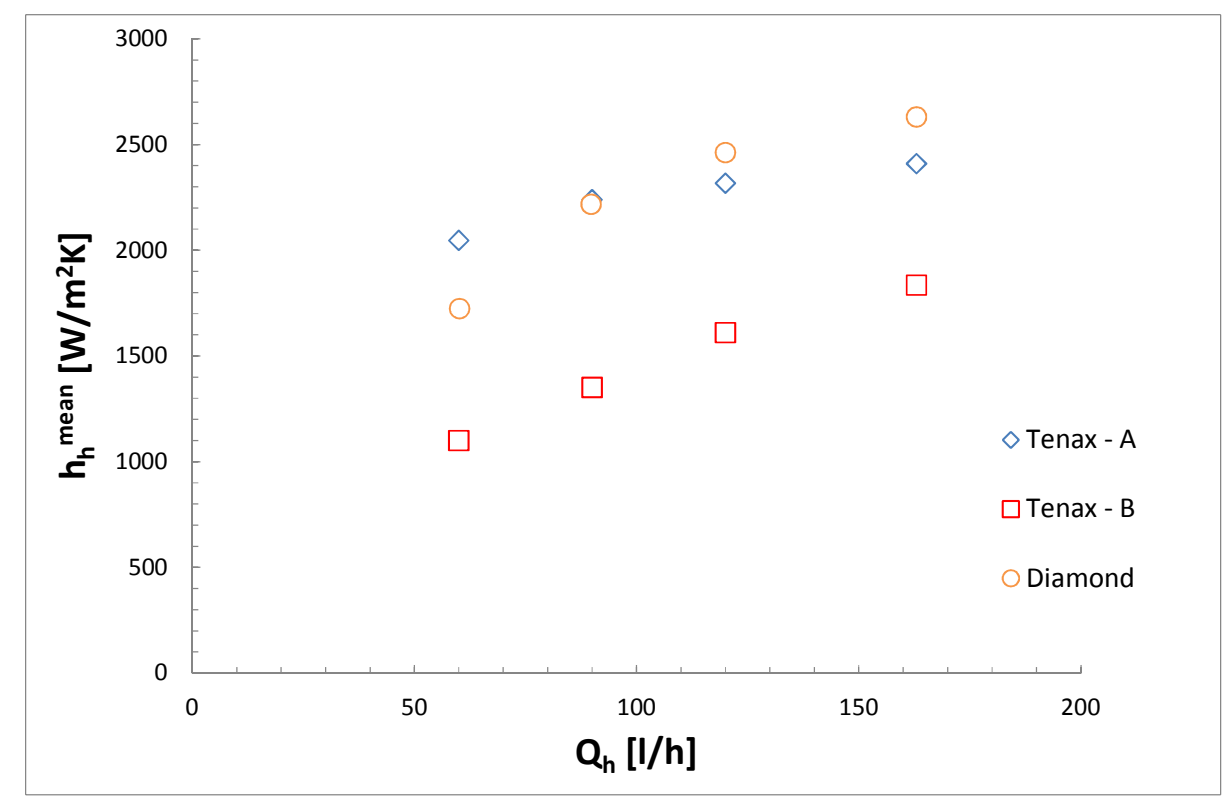

Figure 21. Mean heat transfer coefficient versus hot channel flow rate: comparison of different spacers.

Given the different channel height $h_{c h}$ provided by the different spacers, a more appropriate comparison can be done by plotting the Nusselt number versus the Reynolds number. This latter was conventionally calculated on the basis of the total mass flow rate and twice the channel height, and thus coincides with the Reynolds number that would be established in the absence of the spacer. The results are shown in Figure 22. They are compared with the Nusselt number in an equivalent channel empty of spacer, for which a value of 5.38 was calculated by analytically solving the heat transfer equation for laminar flow in a flat rectangular channel confined by an adiabatic wall on one side and a constant heat flux wall on the other. As already found by other authors $[25,27,28]$, for a given mass flow all the spacers give rise to higher Nusselt numbers compared to the empty channel, thus confirming how the presence of the spacer enhances heat transfer by promoting mixing. Even though mean heat transfer coefficients for Diamond and Tenax-A spacers are close to each other, Nusselt numbers for Diamond spacer are higher than those for Tenax-A at all Reynolds numbers considered here. This can be explained by the larger thickness of the Diamond spacer compared to 
Tenax-A (3.5mm vs. $3.0 \mathrm{~mm})$, leading to a higher hydraulic diameter, which directly influences the Nusselt number estimation.

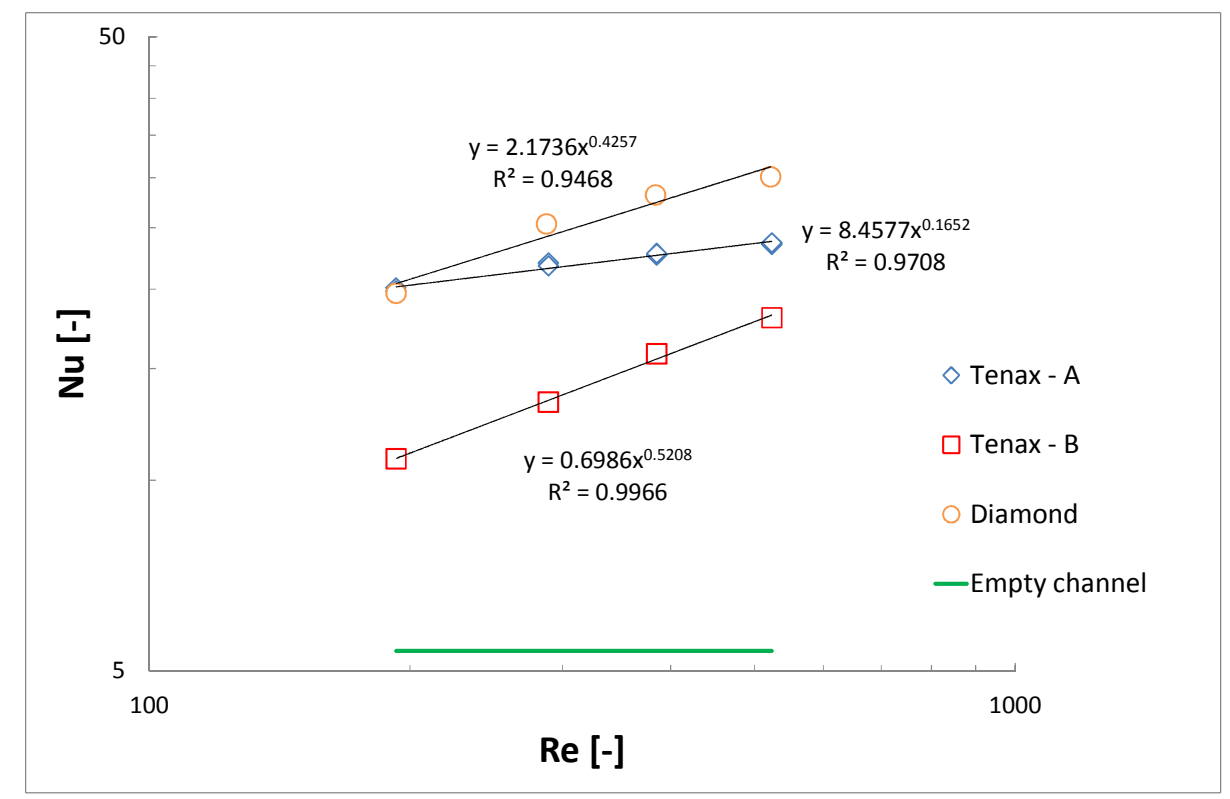

Figure 22. Nusselt number versus Reynolds number: comparison of different spacers.

The data plotted in Figure 22 can be interpolated by a power law:

$$
N u=A \operatorname{Re}^{\alpha}
$$

Figure 22 and Table 3 report A and $\alpha$ values obtained for each spacer configuration. Although both Tenax-A and Diamond spacers present oblique wires close to the conductive TLC wall, the corresponding $\alpha$-values are quite different ( 0.43 for Diamond spacer, 0.17 for Tenax-A spacer), an occurrence which requires further experiments and analysis to be properly explained. 
Table 3: A and $\alpha$ values obtained for spacers investigated.

\begin{tabular}{|c|c|c|}
\hline Spacer & A & $\boldsymbol{\alpha}$ \\
\hline Tenax $-A$ & 8.46 & 0.17 \\
\hline Tenax $-B$ & 0.70 & 0.52 \\
\hline Diamond & 2.17 & 0.43 \\
\hline
\end{tabular}

For a comparison with literature data, some findings from previous works have been considered. In particular, the articles published by Martinez et al. in 2006 [26] and Phattaraniwik et al. in 2003 [29] were analysed and relevant experimental data were extracted and re-processed in order to estimate the Reynolds and Nusselt number to be compared with the values obtained in the present work. Notwithstanding the significant difference in channel thickness and spacer geometry, some important similarities were found. In fact, when analysing the trends of non-dimensional numbers, $\mathrm{Nu}$ and $R e$, for a woven spacer $\left(h_{c h}=0.45 \mathrm{~mm}, R e\right.$ ranging from 50-350), Martinez et al. [26] found the relationship (after re-adapting according to the definition of $R e$ and $N u$ for the empty channel, as already explained above):

$$
N u=0.229 \operatorname{Re}^{0.72}
$$

Eq. 23 gives $N u$ values around 12 for $R e$ around 250, thus very close to the ones reported in the present study for the spacer Tenax-B, although the power-law dependence on $R e$ has a slightly smaller exponent in our case.

Phattaranawik et al. [29] analysed the trend of $h$ and Nusselt number for different non-woven spacers. They proposed the use of a correlation from previous literature studies [46] adopting the heat-mass transfer analogy (eq.20 in [29]). Re-adapting the correlation to the present definition of $\mathrm{Nu}$ and $\mathrm{Re}$ and considering the geometrical features of the Diamond spacer used in the present work, the following power-law expression is found: 
Starting from this equation, calculations show that for $R e$ around 250 a $N u$ value around 34 is found, compared to a smaller value of about 23 obtained for the Diamond spacer in the present investigation. At the same time, a similar exponent of the power law relating $N u v s R e$ can be observed in the two cases.

Although being only qualitative comparisons, given the different geometries and experimental approaches adopted in previous literature works, the fair agreement found between the TLC-IA-TP technique and such previous findings encourage towards a further use of the hereby presented experimental technique for wider investigations of the behaviour of spacer filled channels for membrane distillation.

\section{CONCLUSIONS}

A space-resolved thermographic technique based on thermochromic liquid crystals (TLCs) was developed in order to estimate the temperature and heat transfer coefficient distributions in spacerfilled channels for Membrane Distillation modules. A purposely designed experimental apparatus was set-up and used for testing different spacer configurations. Raw images were recorded and post-processed using the Matlab ${ }^{\circledR}$ Image Processing Toolbox. The technique proved to be able to provide local distributions of temperature on the membrane surface, heat transfer and thermal polarization coefficients, allowing these quantities to be correlated with the geometrical features of each spacer. Preliminary results show that:

- Oblique wires generate velocity components perpendicular to the conductive wall, which improve convective heat transfer in the channel;

- Minimum heat transfer coefficients occur where spacers are in direct contact with the wall;

- Low heat transfer coefficients are observed downstream of these direct contact areas;

- For all the spacers considered here, a significant enhancement of the average Nusselt number (from 2.5 up to 5.8 times that in an empty channel) is observed. Among them, the symmetric 
and wide meshed Diamond spacer seems better to promote mixing conditions and heat transfer;

- In the range investigated, the Nusselt number was found to increase with Re following a weak power law, with exponents ranging from 0.17 to 0.52 according to the spatial configuration tested.

The technique has proved to be quite promising and further investigations will be performed in order to fully characterize mixing and heat transfer phenomena promotion in spacer-filled channels for Membrane Distillation modules.

\section{ACKNOWLEDGEMENTS}

This work was carried out with the financial support of the MEDIRAS project within the EU-FP7 research programme (contract number TREN/FP7EN/218938). Tenax SpA, Solar Spring GmbH and NSW (poly-net ${ }^{\circledR}$ ) are gratefully acknowledged for providing the spacer material for the tests.

\section{NOMENCLATURE}

\section{Symbol}

A

$d_{h}$

$d_{h 0}$

$d_{w}$

$h$

$h_{c h}$

$L$

$l_{m}$

$N$

$\mathrm{Nu}$

$\mathrm{Pr}$

$q$

$Q$

Re

$T$

$\bar{u}$

$x$

$y$

$\alpha$

$\varepsilon$

$\lambda$

$\mu$
Quantity

Pre-exponential factor

Hydraulic diameter

Void hydraulic diameter $\left(\approx 2 \cdot \mathrm{h}_{\mathrm{ch}}\right)$

Wire diameter

Heat transfer coefficient

Channel height (= spacer thickness)

Height/Length

Spacer wire pitch

Molar flux

Nusselt number, $\left(h \cdot d_{h o} / \lambda\right)$

Prandtl number

Heat flux

Flow rate

Reynolds number, $\left(\rho \cdot \bar{u} \cdot d_{h o} / \mu\right)$

Temperature

Mean velocity in the channel

Main flow direction (longitudinal)

Orthogonal direction

Exponential factor

Voidage (porosity)

Thermal conductivity

Viscosity

\section{SI Unit}

$\mathrm{m}$

$\mathrm{m}$

$\mathrm{m}$

$\mathrm{W} /\left(\mathrm{m}^{2} \mathrm{~K}\right)$

$\mathrm{m}$

$\mathrm{m}$

$\mathrm{m}$

$\mathrm{mol} /\left(\mathrm{m}^{2} \mathrm{~s}\right)$

-

$\mathrm{W} / \mathrm{m}^{2}$

$\mathrm{m}^{3} / \mathrm{s}$

${ }^{\circ} \mathrm{K}$

$\mathrm{m} / \mathrm{s}$

$\mathrm{m}$

$\mathrm{m}$

$-$

$\mathrm{W}(\mathrm{mK})$

$\mathrm{Pa} \cdot \mathrm{s}$ 


$\begin{array}{lll}\rho & \text { Density } & \mathrm{Kg} / \mathrm{m}^{3} \\ \theta & \text { Reduced temperature } & { }^{\circ} \mathrm{C} \\ \sigma & \text { Uncertainty } & \text { variable } \\ \tau & \text { Temperature Polarization coefficient } & - \\ \zeta & \text { Angle between crossing wires } & { }^{\circ}\end{array}$

\section{Subscripts}

$c$

$h$

pol

$T L C$
Cold

Hot

Polycarbonate

Thermochromic Liquid Crystals

\section{REFERENCES}

[1] K.W. Lawson, D.R. Lloyd, Membrane distillation, J. Membr. Sci. 124 (1997) 1-25.

[2] M.S. El-Bourawi, Z. Ding, R. Ma, M. Khayet, A framework for better understanding membrane distillation separation process, J. Membr. Sci. 285 (2006) 4-29.

[3] A. Cipollina, J. Koschikowski, F. Gross, D. Pfeifle, M. Rolletschek, R. Schwantes, Membrane distillation: solar and waste heat driven demonstration plants for desalination, International Workshop on Membrane Distillation and Related Technologies, October 9-12 (2011) Ravello (Italy)

[4] J. Koschikowski, M. Wieghaus, M. Rommel, V.S. Ortin, B.P. Suarez, J.R. Betancort Rodríguez, J.R., Experimental investigations on solar driven stand-alone membrane distillation systems for remote areas, Desalination 248 (1-3) (2009) 125-131.

[5] R. Porrazzo, A. Cipollina, M. Galluzzo, G. Micale, A neural network-based optimizing control system for a seawater-desalination solar-powered membrane distillation unit, Computers \& Chemical Engineering, 54 (2013) 79- 96. Doi. 10.1016/j.compchemeng.2013.03.015

[6] J. Koschikowski, M.Wieghaus, M. Rommel, Solar thermal-driven desalination plants based on membrane distillation, Desalination 156 (2003) 295-304.

[7] Schwantes R., Cipollina A., Gross F., Koschikowski J., Pfeifle D., Rolletschek M., Subiela V., Membrane Distillation: solar and waste heat driven demonstration plants for desalination, Desalination (2013). Doi:10.1016/j.desal.2013.04.011

[8] R.W. Schofield, A.G. Fane, C.J.D. Fell, Heat and mass transfer in membrane distillation, J. Mem. Sci. 33 (3) (1987) 299-313.

[9] A. Cipollina, M. G. Di Sparti, A. Tamburini, G. Micale. Development of a Membrane Distillation module for solar energy seawater desalination, Chem. Eng. Res. Des. 90 (2012) 2101-2121.

[10]D. Winter, J. Koschikowski, M. Wieghaus, Desalination using membrane distillation: Experimental studies on full scale spiral wound modules, J. of Mem. Sci. 375 (1-2) (2011) 104112.

[11]L. Martínez-Díez, M.I. Vázquez-González, F.J. Florido-Díaz, Study of membrane distillation using channel spacers, Journal of Membrane Science 144 (1-2) (1998) 45-56.

[12]C.P. Koutsou, S.G. Yiantsios, A.J. Karabelas, Direct numerical simulation of flow in spacerfilled channels: Effect of spacer geometrical characteristics, Journal of Membrane Science 291 (1-2) (2007) 53-69. 
[13]Y.-L. Li, K.-L. Tung, CFD simulation of fluid flow through spacer-filled membrane module: Selecting suitable cell types for periodic boundary conditions, Desalination 233 (2008) 351358.

[14]A. Tamburini, G. La Barbera, A. Cipollina, M. Ciofalo, G. Micale, CFD simulation of channels for direct and reverse electrodialysis, Desalination and Water Treatment, 48 (2012) 370-389.

[15]L. Gurreri, A. Tamburini, A. Cipollina, G. Micale, CFD analysis of the fluid flow behaviour in a reverse electrodialysis stack, Desalination and Water Treatment, 48 (2012) 390-403.

[16]L. Gurreri, A. Tamburini, A. Cipollina, G. Micale, M. Ciofalo, CFD Simulation of Mass Transfer Phenomena in Spacer Filled Channels for Reverse Electrodialysis Applications, Chemical Engineering Transactions 32 (2013) 1879-1884. Doi: 10.3303/CET1332314.

[17]J. Phattaranawik, R. Jiraratananon, A. G. Fane. Effects of net-type spacers on heat and mass transfer in direct contact membrane distillation and comparison with ultrafiltration studies, Journal of Membrane Science 217 (2003a) 193-206.

[18]L. Martìnez, J.M. Rodrìguez-Maroto, Effects of membrane and module design improvements on flux in direct contact membrane distillation, Desalination 205 (1-3) (2007) 97-103

[19]X. Yang, R. Wang, A.G. Fane, Novel designs for improving the performance of hollow fiber membrane distillation modules, Journal of Membrane Science 384 (1-2) (2011) 52-62.

[20]A. Cipollina, G. Micale, L. Rizzuti, Membrane distillation heat transfer enhancement by CFD analysis of internal module geometry, Desalination and Water Treatment 25 (2011) 195-209.

[21]A. Cipollina, A. Di Miceli, J. Koschikowski, G. Micale, L. Rizzuti, CFD simulation of a membrane distillation module channel, Desalination and Water Treatment 6 (2009) 177-183.

[22]A. R. Da Costa, A. G. Fane. Net-type spacers: effect of configuration on fluid flow path and ultrafiltration flux. Ind. Eng. Chem. Res. 33 (1994) 1845-1851.

[23]M. Shakaib, M. Ehtesham-ul Haq, I. Ahmad, R.M. Yunus, Modeling the effect of spacer orientation on heat transfer in membrane distillation, World Academy of Science, Engineering and Technology 72 (2010) 279-282.

[24]M. Shakaib, S.M.F. Hasani, I. Ahmed, R.M. Yunus, A CFD study on the effect of spacer orientation on temperature polarization in membrane distillation modules, Desalination 284 (2012) 332-340.

[25]J. Phattaranawik, R. Jiraratananon, A.G. Fane, C. Halim, Mass flux enhancement using filled channels in direct contact membrane distillation, Journal of Membrane Science (2001) 193201.

[26]L. Martìnez, J.M. Rodrìguez-Maroto, Characterization of membrane distillation modules and analysis of mass flux enhancement by channel spacers, Journal of Membrane Science 274 (2006) 123-137.

[27]M.N. Chernyshov, G.W. Meindersma, A.B. de Haan, Comparison of spacers for temperature polarization reduction in air gap membrane distillation, Desalination 183 (2005) 363-374.

[28]Y. Yun, J. Wang, R. Ma, A.G. Fane, Effects of channel spacers on direct contact membrane distillation, Des. \& Water Treatment 34 (2011) 63-69.

[29]J. Phattaranawik, R. Jiraratananon, A. G. Fane, Heat transport and membrane distillation coefficients in direct contact membrane distillation, Journal of Membrane Science 212 (2003b) 177-193.

[30]X. Yang, H. Yu, R. Wang, A.G. Fane, Analysis of the effect of turbulence promoters in hollow fiber membrane distillation modules by computational fluid dynamic (CFD) simulations, Journal of Membrane Science 415-416 (2012) 758-769. 
[31]S. Al-Sharif, M. Albeirutty, A. Cipollina, G. Micale, Modelling flow and heat transfer in spacer-filled membrane distillation channels using open source CFD code, Desalination 311 (2013) 103-112.

[32]C.-C. Wang, On the heat transfer correlation for membrane distillation, Energy Conversion and Management 52 (4) (2011) 1968-1973.

[33]A. Tamburini, A. Parlapiano, A. Cipollina, M. Ciofalo, G. Micale, Temperature Distribution Analysis in Spacer Filled Channels for Membrane Distillation, Procs. 7th International Symposium on Turbulence, Heat and Mass Transfer, Palermo, Italy, 24-27 September 2012, pp. 299-302, K. Hanjalic, Y. Nagano, D. Borello and D. Jakirlic, eds, Begell House Inc., New York, 2012.

[34]A. Tamburini, G. Micale, M. Ciofalo, A. Cipollina, Experimental Analysis via Thermochromic Liquid Crystals of the temperature local distribution in Membrane Distillation modules, Chemical Engineering Transactions 32 (2013) 2041-2046. Doi: 10.3303/CET1332341.

[35]L.C.R Hallcrest, Hallcrest Handbook of Thermochromic Liquid Crystal Technology, http://hallcrest.com/randt.cfm (1991).

[36]V.U. Kakade, G.D. Lock, M. Wilson, J.M. Owen, J.E. Mayhew, Accurate heat transfer measurements using thermochromic liquid crystal. Part 2: Application to a rotating disc, International Journal of Heat and Fluid Flow 30 (2009) 950-959.

[37]P. J. Newton, Y. Yan, Nia E. Stevens, S. T. Evatt, Gary D. Lock, J. Michael Owen, Transient heat transfer measurements using thermochromic liquid crystal. Part 1: An improved technique, International Journal of Heat and Fluid Flow 24 (2003) 14-22.

[38]M. Ciofalo, I. Di Piazza, J. A. Stasiek, Investigation of Flow and Heat Transfer in CorrugatedUndulated Plate Heat Exchangers, Heat and Mass Transfer, 36 (2000) 449-462.

[39]J. Stasiek, M. Ciofalo, M. Wierzbowski, Experimental and numerical simulations of flow and heat transfer in heat exchanger elements using liquid crystal thermography, Journal of Thermal Science 13 (2) (2004) 133-137.

[40]J.A. Stasiek, T.A. Kowalewski, Thermochromic Liquid Crystals applied for heat transfer research, Opto-electronics Review 10(1) (2002) 1-10.

[41]W.J. Hiller, S. Koch, T.A. Kowalewski, Three-dimensional structures in laminar natural convection in a cubic enclosure, Exp. Thermal and Fluid Sci., 2(1) (1989) 34-44.

[42]M. Ciofalo, M. Signorino, M. Simiano, Tomographic particle-image velocimetry and thermography in Rayleigh-Bénard convection using suspended thermochromic liquid crystals and digital image processing, Experiments in Fluids 34 (2003) 156-172.

[43]H. Al-Fulaij, A. Cipollina, D. Bogle, and H. Ettouney, Once through multistage flash desalination: gPROMS dynamic and steady state modelling, Desalination and Water Treatment 18 (2010) 46-60.

[44] M. Tedesco, A. Cipollina, A. Tamburini, W. van Baak, G. Micale, Modelling the Reverse ElectroDialysis process with seawater and concentrated brines, Desalination and Water Treatment 49 (2012) 404-424.

[45]R.J. Moffat, Describing the uncertainties in experimental results, Experimental Thermal and Fluid Science 1 (1988) 3-17.

[46]A.R. Da Costa, A.G. Fane, D.E. Wiley, Spacer characterization and pressure drop modeling in spacer-filled channels for ultrafiltration, J. Membr. Sci. 87 (1994) 79-98. 